\title{
Ciudadanía sexual y discordancia de género: revisión teórica y reflexiones problemáticas
}

\author{
Sexual citizenship and gender discordance: theoretical review and \\ problematic reflections
}

\author{
Sinuhé Estrada-Carmona \\ Facultad de Humanidades \\ Universidad Autónoma de Campeche, México. \\ sinuhee@hotmail.com \\ https://orcid.org/0000-0002-9605-8148
}

\begin{abstract}
Resumen
El propósito del presente trabajo es exponer los argumentos más representativos del concepto de ciudadanía sexual y sus implicaciones para el ejercicio de derechos de personas que viven discordancia de género particularmente en México. Se detalla un recorrido teórico que invita a la reflexión crítica de los desafíos en la construcción de ciudadanía sexual basada en el sistema binario del sexo y del género, así como para el estudio de las diversidades sexuales. Concluyendo, por un lado, que en la actualidad el sistema binario está siendo rebasado y, por otro lado, se está abriendo la oportunidad de desnaturalizar, desesencializar y tal vez desbinarizar las identidades de género.

Palabras clave: ciudadanía; ciudadanía sexual; derechos sexuales; diversidad; discordancia de género.
\end{abstract}

\section{Abstract}

The purpose of this work is to present the most representative arguments of the concept of sexual citizenship and its implications for the exercise of the rights of people living in gender discordance, particularly in Mexico. A theoretical path is detailed that invites to think critically on the challenges in the construction of sexual citizenship based on the binary system of sex and gender, as well as for the study of sexual diversities. Concluding, on one hand, that nowadays the binary system has been surpassed and on the other hand that the opportunity to denaturalize, de-essentialize and perhaps debinarize gender identities opens.

Key words: citizenship; sexual citizenship; sexual rights; diversity; gender discordance 


\section{RELES \\ OLAVIDE Revista del Laboratorio lberamencicano para \\ s e v I L L a el Estudio Sociohistórico de las Sexualidades}

Cómo citar este trabajo: Estrada-Carmona, Sinuhé (2021). Ciudadanía sexual y discordancia de género: revisión teórica y reflexiones problemáticas. Revista del Laboratorio Iberoamericano para el Estudio Sociohistórico de las Sexualidades, 5 art. 2, pp: 19-59. https://doi.org/10.46661/ relies.5212

\section{Introducción ${ }^{1}$}

Ciudadanía es la categoría política que legitima el nuevo estatuto del sujeto occidental en la actualidad. A partir del siglo XVIII, dos ejes construyen la nueva subjetividad política moderna: la ciudadanía y los derechos humanos. Sólo aquel que posea o adquiera el estatuto de ciudadano es perceptible de ser considerado humano. Se construye un límite político entre aquellos que pueden ser considerados ciudadanos y quienes quedan fuera de los límites de tal definición sin tener garantizados derechos humanos básicos. Desde el momento en que la noción de "ciudadanía" aparece en el pensamiento político moderno como categoría central para definir la nueva subjetividad moderna, hay sujetos que quedan fuera de tal definición. La exclusión que marca en su mismo fundamento la constitución del ciudadano moderno afecta a diversos sujetos: los niños, las mujeres o los esclavos, entre otros. Desde su origen la ciudadanía se perfila como una categoría política excluyente. Estos diversos ejes que conforman la identidad subjetiva y que marcan la no pertenencia a la ciudadanía son: el género, el sexo, la sexualidad, la raza, la clase social o la nacionalidad (Balza, 2009:231).

En este texto exploraré particularmente el caso de las personas que viven lo que se ha definido desde la psiquiatría post-moderna como "discordancia de género", antes llamada disforia de género y transexualidad, en relación al ejercicio de sus derechos y la construcción de ciudadanía sexual, a partir de un recorrido crítico de las hipótesis teóricas y los marcos normativos jurídicos y médicos para dar contexto a la situación de los desafíos en México.

\section{Enfoques teóricos y posturas críticas antagónicas}

La ciudadanía sexual y discordancia de género son categorías que interactúan para dar contexto político, social y económico a sujetos y colectivos en la lucha por existir y ser reconocidos por el Estado. Las aproximaciones teóricas que han intentado explicar y describir dichas categorías son, hoy en día, diversas, multidisciplinarias y en algunos casos antagónicas.

El estudio de la sexualidad no es tarea sencilla, considerando que el concepto en sí es complejo de definir. Sin embargo, apegándose a la idea de sexualidad de la Organización Mundial de la Salud se puede entender como:

"un aspecto central del ser humano que está presente a lo largo de su vida. Abarca el sexo, las identidades y los roles de género, la orientación sexual, el erotismo, el placer, la intimidad y la reproducción. Se siente y se expresa a través de pensamientos, fantasías, deseos, creencias,

\footnotetext{
${ }^{1}$ Agradezco a las Doctoras Gina Villagómez, Rocío Quintal y Rebelin Echeverria de la Universidad Autónoma de Yucatán por su poyo, aportaciones y sugerencias
} 
actitudes, valores, comportamientos, prácticas, roles y relaciones. Si bien la sexualidad puede incluir todas estas dimensiones, no todas ellas se experimentan o expresan siempre. La sexualidad está influida por la interacción de factores biológicos, psicológicos, sociales, económicos, políticos, culturales, éticos, legales, históricos, religiosos y espirituales" (OMS, 2006 p.5).

Dicha conceptualización trasciende el orden de lo biológico y lo psicológico, incorporado aspectos que se entrelazan con la idea de ciudadanía. Ser ciudadano, implica tener derechos políticos, sociales, económicos, culturales y acceso a las tecnologías de comunicación e información. Pero, paradójicamente, su declaración en el discurso jurídico y en su contraparte, los derechos civiles, políticos y sociales, demuestra que no se concretan estos derechos en acciones claras para toda la población (Enríquez y Martínez, 2016).

En este sentido, sexualidad y ciudadanía forman parte de los discursos teóricos que conforman los referentes biológicos, sociales y culturales a partir de los cuales se construyen identidades jurídicas reconocidas o no por el Estado. Puede decirse que la ciudadanía "como constructo simbólico y criterio de organización sociopolítica clasifica y diferencia al ciudadano del que no lo es, sea nativo o de origen extranjero, independientemente de su procedencia, trayectoria y características personales o grupales" (Barañano et al. 2007:21).

Para Enríquez y Martínez (2016) el cuerpo cuestiona la condición social, cultural, política, y trastoca el signo social de la ciudadanía formal. Esto obliga a repensar la ciudadanía, en la cual la persona pasa por el reconocimiento de su cuerpo y del de los otros.

Así, como describiré a continuación, la construcción del sujeto "transexual y transgénero" ha tenido su propio devenir histórico y político a partir del discurso médico y, al paso del tiempo se ha resignificado a partir de los estudios teóricos sobre ciudadanía sexual.

La sexología como ciencia nació a finales del siglo XIX, surgiendo como un nuevo campo dentro de la psiquiatría y psicología, específicamente relacionada con lo que se denominó "sexualidad humana". Este campo - sexología - desarrolló teorías de comportamiento sexual y observaciones registradas de actividad sexual basada en historias de casos de las llamadas "perversiones" (inicialmente homosexualidad, pero poco después sadismo, masoquismo, fetichismo, etc.). Estas historias de casos fueron inscritas en textos sexológicos como base para la especulación científica. La sexología "hizo" los "tipos de personas" que se pueden encontrar en esas historias de casos (Crozier, 2008:375). A partir de ahí, el tema particular de la construcción del "sujeto-trans", -hoy llamado discordante de género- ha tenido su propio camino de estudio.

Los aportes teóricos de la hoy se denomina discordancia de género se pueden categorizar en tres grupos. Los estudios médico-esencialistas (Fine, 2011; De Vicente, Berdullas y Castilla, 2012; García Falgueras et al., 2005; Segovia y Guillamón, 1993; Zubiaurre-Elorza et al., 2013; Carrillo et al., 2010; Bao y Swaab, 2011; Fernández y Pásaro, 2017; Junger, et al. 2014; Smith, Junger, Derntl y Habel, 2015; Theisen, et al. 2019) que afirman que las características biológicas (genético-anatomofisiológicas) de las personas son inalterables y anteriores a la cultura, así como la hipótesis del determinismo genético, hormonal y cerebral de la identidad sexo-genérica y su inmutabilidad.

Se afirma por ejemplo que:

"Durante el período intrauterino, el cerebro humano se desarrolla en la dirección masculina a través de la acción directa de la testosterona de un niño, y en la dirección femenina a través de la ausencia de esta hormona en una niña. Durante este tiempo, se programa la identidad de género (el sentimiento de ser hombre o mujer), la orientación sexual y otros comportamientos. Como la diferenciación sexual de los genitales tiene lugar en los primeros 2 meses de embarazo, y la diferenciación sexual del cerebro comienza durante la segunda mitad del embarazo, estos dos procesos pueden verse influenciados independientemente el uno del otro, lo que resulta en 
transexualidad. Esto también significa que, en el caso de un género ambiguo al nacer, el grado de masculinización de los genitales puede no reflejar el mismo grado de masculinización del cerebro. Se han encontrado diferencias en las estructuras y las funciones cerebrales que están relacionadas con la orientación sexual y el género." (Swaab, 2007:431).

Por otra parte, los estudios socio-construccionistas (De Beauvoir, 1981; Stoller, 1968; Coll-Planas, 2010; Wittig, 2006; Suárez-Villegas, 2006; Butler, 2002, 2007; Money, 1975, 1994; García Ruiz y De Dios, 2000; Preciado, 2019), que plantean argumentos relacionados con la influencia y condicionamiento cultural, social y político en la construcción de las identidades sexo-genéricas; así como la desnaturalización, fluidez y maleabilidad de la sexualidad y sus prácticas. Una de las referencias más simbólicas en relación con las hipótesis socio-construccionistas es la famosa cita de Simone de Beauvoir:

"El Ser no existe y no debe de confundirse con llegar a ser, el ser, según la filosofía existencialista, es siempre un sujeto tal como se manifiesta. Para los seres humanos, para los hombres como para las mujeres, el ser no es algo, ninguna esencia definitiva: No se nace mujer: se llega a serlo." (de Beauvoir, 1981:371).

Las anteriores posturas teóricas se han presentado históricamente como mutuamente excluyentes e imposibles de conciliar y alrededor de ellas están los estudios sobre condiciones bio-psicosocioculturales, los cuales conforman un conjunto amplio de estudios de sujetos "trans" o "no binarios" asociados con diversas condiciones como la salud física, especialmente aspectos relacionados a la terapia de remplazo hormonal y endocrinología (Dahl, Feldman, Goldberg y Jaberi, 2006; Bradford, Reisner, Honnold y Xavier, 2013; den Heijer, Bakker y Gooren, 2017), VIH y factores de riesgo (De Santis, 2009), salud mental y psiquiatría (Zarazúa, Salinas, Negrete y Ruíz, 2015; Grossman y D'Augelli, 2007; Prunas, et al. 2014; Heylens, et al. 2014) aspectos oncológicos (Gooren, Bowers, Lips y Konings, 2015), aspectos pediátricos (Castilla-Peón, 2018; Olson, Durwood, DeMeules y McLaughlin, 2016), aspectos del bienestar/malestar psicosocial (Bockting, Miner, Swinburne, Hamilton y Coleman, 2013; Boza y Nicholson, 2014; Rimes, Goodship, Ussher, Baker y West, 2019; Bouman, et al. 2017; Stewart, O'Halloran y Oates, 2018), así como de estándares y protocolos de acompañamiento bio-psico-social (Coleman, et al. 2012; Dèttore, et al. 2015; López-Guzmán, 2018; Ehrensaft, Giammattei, Storck, Tishelman y Keo-Meier, 2018; Domínguez, Ramírez y Arrivillaga, 2018; Ortega-Pavesio, 2019).

Los estudios médicos, psicológicos y sociales de la discordancia de género que se produjeron desde la segunda mitad del siglo XX se han diversificado ampliamente. De tal forma que, a principios de los años 90's, comenzaron a relacionarse con el concepto emergente de ciudadanía sexual, derivado de los movimientos sociopolíticos de los colectivos de la diversidad sexual de los años 80's en Europa y Estados Unidos. Así, la idea de ciudadanía sexual surge y se enriquece desde su inicio, a principios de los años 90's, a la par de las formas de construcción de democracia y de las luchas por los derechos civiles de minorías sexuales en los distintos países occidentales (Johnson, 2017).

Cargadas de implicaciones corporales, las sexualidades no se reducen a lo biológico. Es más, justamente por tener implicaciones corporales, cuerpos en relación, personas en relación, es que las sexualidades no se reducen a lo biológico. Sus implicaciones abordan lo cultural y lo político. Como nos recuerda el dispositivo de la sexualidad foucaultiano, sobre el sexo se tiende un velo que distingue entre lo normal y lo patológico, entre lo culturalmente aceptado/negado/negociado y lo políticamente insumiso/bloqueado/disputado. Las sexualidades, de esta manera, constituyen un campo de disputa, un ámbito de politicidad (Arguello, 2012).

Del reconocimiento del atributo político de la sexualidad surge la idea de que es necesaria la defensa de la integridad de la persona (Amuchástegui, y Rivas, 2004). En el caso de los sujetos transexuales, lo que parece resultar 'problemático' para la sociedad y el Estado, no son los actos que puedan

Revista del Laboratorio Iberoamericano para el Estudio Sociohistórico de las Sexualidades https://doi.org/10.46661/relies.5212 
cometer, sino su "hibridez" en relación con la identidad de género (Dellacasa, 2014), y dicha identidad se ha convertido en un elemento fundamental de la construcción de ciudadanía (Weeks, 1998, 2018; Plummer, 2001).

En este sentido, las investigaciones sobre ciudadanía sexual se pueden describir en dos dimensiones: 1. Temporal, es decir, los aportes de finales de siglo XX (1990-1999) y los de inicios del siglo XXI (2001-2019); y 2. Geográfica, es decir, los aportes anglosajones y los de otras regiones, particularmente Latinoamérica y México.

Dicha distinción es relativa a las trayectorias de los diversos movimientos sociopolíticos de colectivos de la diversidad sexual que han tenido lugar en diferentes momentos y países con diferentes formas de gobierno.

Los aportes teóricos de la ciudadanía sexual de finales del siglo XX se caracterizan principalmente por poner en la mesa de debate de las ciencias sociales los argumentos sobre los limites sociopolíticos de la vida privada (íntima/sexual) y la vida pública (ciudadanía) (Giddens, 1992; Evans, 1993, 2007; Waites, 1996; Richardson, 1998; Plummer, 1995, 2001).

"El ciudadano sexual es un fenómeno en el mundo erótico, y un jugador en el ámbito político y cultural, un producto de la nueva primacía de la subjetividad sexual en las sociedades contemporáneas. Viviendo en la fatídica coyuntura de los reclamos privados de espacio, autodeterminación y placer, y reclamos públicos de derechos, justicia y reconocimiento, el ciudadano sexual es un ser híbrido, que nos dice mucho sobre el ritmo y la escala de la transformación cultural y nuevas posibilidades del yo y la identidad" (Weeks, 1998:35).

Dichos aportes sentaron las bases conceptuales y discursivas que han dado lugar a un ámbito de estudio y análisis emergente necesario en las ciencias sociales, describiendo cómo el concepto de ciudadanía sexual es particularmente útil para resaltar la naturaleza heteronormativa de la forma en que muchos derechos de ciudadanía se construyeron originalmente y, el por qué obtener tales derechos a veces puede tener consecuencias normalizadas dado su origen en un modelo heterosexual (Johnson, 2017).

El debate académico de la ciudadanía sexual continua hasta la fecha diversificando sus argumentos (Richardson, 2017, 2018). Lo que se ha escrito desde inicios del siglo XXI ha sido en relación con los derechos humanos, en particular los derechos sexuales de personas no heterosexuales y de género no normativo a través de los análisis de la ciudadanía lésbica, gay y bisexual (Ryan-Flood, 2009; Richardson y Monro, 2012, Monro, 2015), la ciudadanía intersexual (Grabham, 2007; Cabral, 2003), la ciudadanía transgénero y transexual (Whittle, 2002; Hines, 2009; Monro, 2005), la ciudadanía sexual de sujetos que viven alguna discapacidad (Tallis, 2005; Siebers, 2008, Acosta, et al. 2015), la ciudadanía sexual como vía de acceso al crédito y al capital (Bell y Binnie, 2000), así como la idea de justicia sexual y ciudadanía (Weeks, 2018).

Por otra parte, un campo emergente de análisis tiene que ver con la geopolítica de los estudios sobre ciudadanía sexual, los cuales comenzaron en Gran Bretaña, Estados Unidos, Canadá y Australia asumiendo movimientos sociales y realidades sociopolíticas anglosajonas capitalistas. Sin embargo, el debate de la ciudadanía sexual se ha extendido a otras latitudes como la región AsiaPacífico (Boelstorff, 2005, 2007; Benedicto, 2014; Jackson, 2011; Mackie y McLelland, 2015; Yue y Zubillaga-Pow, 2012), que en contraste con Estados Unidos donde la autoconciencia gay es descrita en singular, uno está "en el closet" o "fuera del closet", pero uno solo tiene un verdadero Yo (Self), los gays en las culturas de Asia-Pacifico describen sus despertares como una "apertura", no simplemente para uno mismo, sino para un mundo social, para grupos o para personas que viven en una localidad particular. De esta manera, un individuo no es singular, no está dentro o fuera del "closet", sino que reside a lo largo de un continuo que cambia según la localidad cultural o económica que habita.

Revista del Laboratorio 
Por otro lado, en Latinoamérica se está atravesando un momento histórico con la emergencia y consolidación de demandas en torno a la ciudadanía sexual, simbolizado en varios países por la reciente sanción de la Ley de matrimonio igualitario y Ley de identidad de género, en busca de justicia social pero aún limitadas en algunos países. Así como con las reacciones de sectores conservadores, liderados por las jerarquías de algunas iglesias, hegemonizadas por el catolicismo, que se oponen a las reformas legales a través de propaganda religiosa disfrazada de derechos humanos en contra de lo que ellos llaman "ideología de género" (Cabral, 2003; Cáceres, et al. 2004; Bianco, et al. 2013; Di Marco, 2012; Moreno, 2014; Cardona-Cuervo, 2016; Jiménez, 2018; Sabsay 2018).

Particularmente en México, los aportes teóricos a la ciudadanía sexual se cruzan con la construcción de significados y prácticas sexuales (Amuchastegui y Rivas, 2008; Parrini y Amuchástegui, 2008), con los análisis de las políticas de educación sexual (Rosales, 2007; Mendoza y Soriano, 2009), con los procesos de politización de la sexualidad (Arguello, 2013), con el papel de la diversidad corporal en la construcción de ciudadanía (Enríquez y Martínez, 2016), con la generación de políticas públicas de turismo LGBTTTI (Woolfolk, Núñez y Ponce, 2016), así como con los análisis de leyes estatales en materia de derechos LGBTTTI (Antonio, 2017). Sin embargo, la fuerte contraofensiva de grupos religiosos y de la derecha política que promueven las protestas en contra de la defensa de derechos de las comunidades LGBTTTI bajo la consigna en contra de la "la ideología de género" dificultan el diálogo para la construcción de políticas públicas para dichas poblaciones.

Las condiciones sociales, económicas, políticas y culturales de las distintas regiones y países son muy diversas y contrastan con las anglosajonas, por lo que la teoría de ciudadanía sexual comienza a adquirir la necesidad de un enfoque local. Tal diversificación ha enriquecido los aportes teóricos, ya que el término "ciudadanía" tiene distintos significados, connotaciones y efectos materiales según el sistema político en el que está incrustado. Cualquier intento de aplicar el concepto de "ciudadanía sexual" más allá de la democracia liberal, capitalista, anglófona y económicamente avanzada debe tener en cuenta esta diversidad (Mackie, 2016:10); así como considerar que los problemas de ciudadanía sexual no son solo políticos en el sentido estricto del gobierno; sino también económicos, sociales y culturales e incluyen derechos de grupos sexuales minoritarios (transexuales y transgénero) para ser reconocidos y representados simbólicamente como legítimos (Bell y Binnie, 2000).

Como se puede observar, los aportes teóricos tanto de la discordancia de género como de la ciudadanía sexual han constituido un campo de estudio importante para las ciencias sociales, sobre todo por su cualidad multidisciplinaria que implica diversos niveles y enfoques de análisis, en algunos casos antagónicos, pero sin duda enriquecedores, que dejan ver desafíos teóricometodológicos que sigan contribuyendo a la acción contextualizada social y política de cada región y país.

La identidad es una temática y un problema epistemológico sobre el que diversos teóricos de distintas disciplinas han discutido. Las reflexiones sobre ella, generalmente, defienden las identidades contingentes, parciales, temporales e históricas y, en menor medida, se aboga por la idea de una identidad estática, fija, y atemporal. Así, las teorías sobre la identidad se han ido reconstruyendo y redefiniendo constantemente (Hall, 2003; Navarrete-Cazales, 2015).

Sin embargo, la identidad no siempre ha representado el mismo problema, para Bauman (2003:40) si el "problema moderno de la identidad" era cómo construirla y mantenerla sólida y estable, el "problema posmoderno de la identidad" es en lo fundamental cómo evitar la fijación y mantener vigentes las opciones. 


\section{El fluir de las identidades}

La identidad es una temática y un problema epistemológico sobre el que diversos teóricos de distintas disciplinas han discutido. Las reflexiones sobre ella, generalmente, defienden las identidades contingentes, parciales, temporales e históricas y, en menor medida, se aboga por la idea de una identidad estática, fija, y atemporal. Así, las teorías sobre la identidad se han ido reconstruyendo y redefiniendo constantemente (Hall, 2003; Navarrete-Cazales, 2015).

Sin embargo, la identidad no siempre ha representado el mismo problema, para Bauman (2003:40) si el "problema moderno de la identidad" era cómo construirla y mantenerla sólida y estable, el "problema posmoderno de la identidad" es en lo fundamental cómo evitar la fijación y mantener vigentes las opciones.

\subsection{La identidad moderna}

Tomando en cuenta la distinción de Bauman, se puede considerar que el problema moderno de la identidad nació con la filosofía griega clásica, cuando la palabra tenía un solo significado, el de su raíz etimológica -latina- identitas, es decir, "igual a uno mismo" incluso "ser uno mismo" o lo que se conoce como principio ontológico (o metafísico) de identidad $(A=A)$ y era utilizado únicamente para hablar de las características propias de un objeto o "del hombre", es decir, su esencia, lo que lo diferenciaba del resto de los objetos. Parménides, por ejemplo, decía que lo existente es inamovible, por un principio lógico: solo podemos pensar lo que realmente es, no podemos pensar en lo que no es. Ahora bien, lo que es, necesariamente permanece, porque si no fuese así, dejaría de ser; por lo tanto, las cosas son inmóviles, es decir, el ser (la realidad) es único y permanente, inmutable (Stewart, 1999).

Adicionalmente, Platón y Aristóteles creían en el conocimiento verdadero de las cosas, para el primero existe un mundo inteligible donde está el verdadero ser de las cosas, para el segundo el Ser se entiende de lo que es accidentalmente o de lo que es en sí, porque accidentalmente alguien puede ser algo, y al mismo tiempo otra cosa (padre y hermano); pero en sí es siempre un hombre. Esto significa que el Ser tiene muchos sentidos, se dice de muchas formas, pero formas que participan de una única y primera forma que las unifica: la entidad, o sea, lo que es en sí (NavarreteCazales, 2015).

Descartes (2005) por su parte, se interesó por la cuestión de la identidad personal y afirmaba que no podemos entender lo que somos hasta que no sepamos qué es lo que podemos conocer-saber con certeza.

Si bien se reconoce la intención de otros filósofos modernos como Hume, Kant y Leibniz de superar el viejo esquema de la identidad esencial, sustancial y unívoca, no lo logran del todo. Sin embargo, describieron aspectos fundamentales para la filosofía y la ciencia moderna en relación con la supuesta naturaleza de la identidad.

La principal angustia relacionada con la identidad de los tiempos modernos era la preocupación por la perdurabilidad. Pensamos en la identidad cuando no estamos seguros del lugar al que pertenecemos; es decir, cuando no estamos seguros de cómo situarnos en la evidente variedad de estilos y pautas de comportamiento y hacer que la gente que nos rodea acepte esa situación como correcta y apropiada, a fin de que ambas partes sepan cómo actuar en presencia de la otra. Por lo que "Identidad" es un nombre dado a la búsqueda de salida de esa incertidumbre, incorporándose a la mentalidad y la práctica modernas ataviada desde el inicio como una tarea individual. Correspondía al individuo encontrar un escape de la incertidumbre (Bauman, 2003:41). 


\subsection{La identidad post-moderna}

Para Choza y Piulats (1999) con Nietzsche y Heidegger se inicia el rechazo de todo centro o identidad última (metafísica) revelando las debilidades, paradojas e inconsecuencias de la metafísica universal de la identidad moderna. La única posible identidad del discurso nietzscheano es precisamente la disolución de toda identidad, la lucha irreconciliable en contra de cualquier forma de identidad. Al mismo tiempo, El Dasein (Ser ahí) Heideggeriano es el ente que somos en cada caso nosotros mismos y que tiene entre otros rasgos la posibilidad de ser. Es un término que expresa puramente el Ser. Esto quiere decir que, a diferencia de los entes no humanos, el hombre es lo que él en cada caso es, que es proyecto de sí mismo, tarea de su propia realización, es decir, el ser humano, el sujeto, es cambiante, está siendo constantemente.

La idea de la identidad se incorporó de la filosofía a las ciencias sociales, en particular a la psicología, a partir de las obras de Erick Erickson, quien a mediados del siglo XX empleó el término egoidentidad en sus estudios sobre los problemas que enfrentan los adolescentes y las formas en que pueden superar los conflictos propios de su etapa de madurez. Erickson afirma que la identidad es "un sentimiento de mismidad y continuidad que experimenta un individuo en cuanto tal (Erickson, 1977: 586); lo que se convierte en la percepción subjetiva que tiene el individuo de sí mismo y que surge cuando se pregunta ¿quién soy? La identidad supone un ejercicio de autorreflexión, a través del cual el individuo pondera subjetivamente sus capacidades y potencialidades, tiene conciencia de lo que es y puede ser como persona; sin embargo, como el individuo no está solo, sino que convive con otros, el autoconocimiento implica reconocerse como miembro de un grupo; lo cual, a su vez, le permite diferenciarse de los miembros de otros grupos. Así, el concepto de identidad aparece relacionado con la subjetividad individual, siendo las perspectivas filosófica y psicológica las que predominan en los primeros trabajos sobre identidad social (Maldonado y Oliva, 2010).

En este sentido, la subjetividad no se puede reducir a un estado únicamente interno, sino a una internalidad que involucra tanto lo psicológico como lo social en una relación dialéctica y cuya naturaleza es histórica y social. La subjetividad se entiende como la organización de los procesos de sentido y significado que aparecen y se configuran de diferentes formas en el sujeto y en la personalidad, así como en los diferentes espacios sociales en los que el sujeto actúa (González, 2002:2).

La subjetividad entendida simultáneamente como significados y sentidos que caracterizan también los diferentes espacios sociales que los individuos constituyen (familia, sala de aula, grupo de amigos, empresa y muchos otros) contribuye a romper con la dicotomía individual-social, internoexterno, intrasubjetivo-intersubjetivo, articulando de forma dialéctica, ambos polos y expresando su carácter, contradictorio, complementario y recursivo (Mitjáns-Martínez, 2008).

Por ello, la identidad es fundamental para poder pensar la sociedad y construirla, no hay sociedad sin sujetos y los sujetos no pueden existir si no están en el marco de una sociedad. Como lo afirma Mélich (2010) cuando partiendo de la moral reflexiona sobre cómo debemos guiarnos en el mundo y establece una serie de comportamientos, actitudes y reglas que debemos seguir, las cuales están dadas desde que nacemos y termina afirmando que esa moral configura nuestra identidad haciendo además una precisión relevante al decir "toda identidad es social" (p.327).

Para Laclau (1994:33), Derrida demostró que la constitución de una identidad siempre se basa en la exclusión de algo y el establecimiento de una jerarquía violenta entre los dos polos resultantes: hombre /mujer, etc. Lo peculiar del segundo término queda así reducido a la función de un accidente, en oposición al carácter esencial del primero. Sucede lo mismo con la relación negroblanco, en que el blanco, desde luego, es equivalente a "ser humano". "Mujer" y "negro" son entonces "marcas" (esto es, términos marcados) en contraste con los términos no marcados de "hombre" y "blanco".

Revista del Laboratorio Iberoamericano para el Estudio Sociohistórico de las Sexualidades https://doi.org/10.46661/relies.5212 
Por su parte, Pachano (2003) añade que la identidad es una evidencia directa que surge de la de la contraposición de realidades que de hecho son distintas en uno o en múltiples aspectos, su materialización solamente se produce posterior a un proceso de construcción social intelectual. Es un proceso en el que interviene decisivamente la creencia, en cuanto a confianza en un futuro común asentado en un pasado que unifica los integrantes del grupo en torno a valores compartidos. En ese sentido, la identidad se construye como la afirmación de los elementos que caracterizan a un grupo humano, a los cuales éste asigna un valor fundamental para su autodefinición y considera, a la vez, como la expresión de "lo normal". Por tanto, la construcción de las identidades es inicialmente la "afirmación" de un conjunto de condiciones o características de un grupo social frente a otro u otros.

En este sentido, Navarrete-Cazales (2015:468) define la identidad como:

"una categoría general que posibilita que tengamos un lugar de adscripción (histórico-temporal) frente a los demás a distinguirnos de los otros (sujetos, instituciones, grupos, familias, comunidades, movimientos sociales, naciones), y decir qué es lo que somos y lo que no somos. No hay posibilidad de identidad que no postule, al mismo tiempo, una alteridad: no sería posible una mismidad sin la existencia de esa otredad. Por su parte, el proceso identificatorio es algo más específico, particular, que implica el análisis del momento del enganche, de la identificación con algo o alguien (sujeto, idea) que nos constituye en un momento particular, específico de nuestra identidad histórica, contextual, ergo cambiante".

La constitución de una identidad social siempre es un acto de poder, por lo tanto, política (sujeto/identidad política). El sujeto para Laclau (1994:79), es la forma pura de la dislocación de la estructura, dicha dislocación permite que el sujeto nunca llegue a una identidad plena, sino temporal, así el sujeto se constituye en los bordes dislocados de la estructura. Por lo tanto, la identidad del sujeto político se construye a partir de actos de identificación que pueden ser de decisión o de poder; la identidad tiene dos elementos constitutivos, por un lado, es movimiento contingente $y$, por otro, marca las diferencias. Esto último va de la mano con la relación existente entre distintas posiciones de sujeto. El sujeto se constituye a partir de distintas posicionalidades, las cuales se encuentran dispersas en el mundo, pero no separadas, sino que se relacionan y diferencian a su vez; ninguna de las posiciones del sujeto logra consolidarse finalmente como separada, hay un juego de sobredeterminación entre las mismas que reintroduce el horizonte de una totalidad imposible (Laclau y Mouffe, 2004:164). Por tanto, la identidad humana no es solo un conjunto de posiciones dispersas, sino también las formas de sobredeterminación que se establecen entre las mismas.

El sujeto construye su identidad a partir de la asunción de distintas posiciones, roles o polos identitarios: un sujeto a lo largo de su historia de vida puede ser científico, padre de familia, político, beisbolista, etcétera $y$, en este sentido, la identidad se reconstruye constantemente por la adquisición de nuevas posiciones y por las resignificaciones que hace cada sujeto de ellas; nuestro ser en el mundo lo conformamos por tantas identidades como nos constituyamos (decisoriamente o no) en él, y decimos decisoriamente o no, porque tenemos algunos "polos identitarios" ya dados históricamente (por ejemplo: ser hijo, hombre o mujer) pero eso no quiere decir que un polo identitario constituya o determine en términos definitorios la identidad de un sujeto. Cabe decir que concebir a los sujetos como políticos es porque tenemos el poder de decidir y actuar, no solo colectivamente sino también individualmente. Las decisiones no son, por supuesto, de libre albedrío, sino que siempre están condicionadas por el contexto y mediadas por otros sujetos, agencias e instituciones, lo que implica relaciones de poder (Navarrete-Cazales, 2015). 


\section{4 ¿Quién ha sido el sujeto trans?}

Los términos transexual, transgénero, travesti y homosexual tienen su origen en el campo de la medicina moderna de finales del siglo XIX, formando un cuerpo de conocimientos que las clasificaron como patologías. Sin embargo, las luchas por los derechos civiles de las llamadas "minorías sexuales" y los estudios en las ciencias sociales desde la segunda de mitad del siglo XX y hasta la fecha, han logrado repensar dichos términos a partir de análisis y críticas multidisciplinarias post-estructuralistas, haciendo énfasis en el papel de los aspectos ideológico/religiosos, políticos, económicos y culturales en la construcción de subjetividades abyectas a la cisheteronormatividad (Preciado, 2019).

\subsection{Lo que ha aportado la medicina-psiquiátrica}

Aunque en la literatura antigua occidental ya se hacía referencia a seres míticos e históricos de ambigüedad sexual, el primer registro moderno de un "tercer sexo" se lo debemos a Karl Heinrich Ulrichs, quien en 1864 acuñó el término nombrándose a sí mismo "Uranista", ni enfermo como aseguraba la medicina, ni criminal como sentenciaban las leyes heredadas de la religión judeocristiana de la época. Ulrichs se definía como un "alma femenina encerrada en un cuerpo masculino". En su teoría, que fue rechazada posteriormente por la medicina, proponía elementos empíricos de sujetos no clínicos a partir de los cuales cuestionó el sistema binario sexual, dejando ver la posibilidad de subjetividades y prácticas sexuales "naturales y legítimas" no binarias que hacían experimentar a algunas personas cierto disconfort por el confinamiento de su "alma femenina en un cuerpo de hombre" (Kennedy, 1981:103).

El 6 de mayo de 1868, Karl Maria Kertbeny le envía una carta manuscrita a Ulrich en la que inventa y usa por primera vez en la historia la palabra "homosexual" para referirse a lo que Ulrich se refería como "Uranista". En ese contexto nace la patologización médica de la homosexualidad y se encarna el binarismo masculino-femenino, hombre-mujer como sistema político normativo de división sexual y de construcción de subjetividades. Sobre la cicatriz de ese corte binario de la ciencia médica moderna se asienta la propiedad, se funda la familia y se lega la herencia. Sobre esa cicatriz se escribe el nombre y se afirma la identidad sexual (Preciado, 2019).

Para 1869, el neurólogo Karl Westphal describió un fenómeno denominado "Die conträre sexualempfinding" (Sentimientos sexuales contrarios) que incluía algunos aspectos de la Transexualidad. Este documento es considerado el primer texto de sexología médica en el que se hace referencia al caso de una mujer que se describía a sí misma con comportamientos masculinos (Crozier, 2008).

Ulrich perdía las esperanzas de su teoría, al ver como su contemporáneo psiquiatra alemán Richard Von Krafft-Ebing en 1879 desestimaba sus aportaciones en torno al "uranismo". En una sección de su libro "Psychopathia Sexualis" Ilamada "Sentimientos homosexuales como una manifestación congénita anormal" Krafft-Ebing documentó el caso de Ulrich como un "vicio perverso y anormal" y en 1894 describió una forma de vestirse, según el sexo contrario, que denomino "metamorphosis sexuales paranoica" (Krafft-Ebing, 1998:222).

Desde un punto de vista más parecido a la teoría del "Uranismo" de Ulrich, Magnus Hirschfeld (18681935), desarrolló la teoría del "tercer sexo" o "estados sexuales intermedios", produciendo un discurso alternativo a los discursos heteronormativos de su época que incluía la posibilidad de un "tercer sexo" además del binario masculino/femenino (Domínguez, García y Hombrados, 2012). En 1910 acuñó el término travestidos, que contenía lo que ahora llamaríamos transexualidad, 
travestismo y feminidad masculina, y más tarde, en 1931, el de transexualismo mental (Balzer, 2011).

Havelock Ellis, en 1913 propuso el término "Eonismo", haciendo referencia al Caballero de Eon, y de "inversión sexo-estética", diferenciándola de la inversión sexual. Iniciándose a partir de sus clasificaciones la separación entre el homosexual y el transexual. Posteriormente Marcuse en 1916 describió un Tipo de inversión psicosexual que se orientaba al cambio de sexo (Gastó, 2006).

Fue hasta 1949 que Cauldwell usó por primera vez el concepto "transexual" en su artículo "Psichopatia transexualis", donde define qué: "Cuando un individuo que está desfavorablemente afectado psicológicamente determina vivir y presentarse como miembro del sexo al que no pertenece, este individuo se puede llamar psicópata transexual. Significa, simplemente, que no está sano mentalmente, y por esto la persona desea vivir en el sexo opuesto". Documentó en su artículo el caso de Earl, una paciente "mujer" que le solicitaba tratamiento hormonal y cirugía para convertirse en un hombre (Cauldwell, 2001:274).

Aunque la primera operación genital documentada fue el caso de Lili Elbe en 1931, (Pauley, 1969), Cauldwell consideraba que no sería recomendable extirpar órganos saludables por estas razones, asumiendo que la adecuación psicológica al cuerpo era mejor mediante la intervención psiquiátrica. Así, se fue consolidando la idea que el sexo se considera verdad natural inmutable, y es la mente la que debe adecuarse a la anatomía (De la Hermosa-Lorenci, 2013).

Para 1966, el endocrinólogo Harry Benjamín popularizó el término transexual y en 1969 el psicólogo John Money creó los conceptos de "Identidad de género" y "reasignación de género", con la intención de englobar distintos estados cuya característica básica es una alteración de la identidad sexual y de género. Money sugirió el concepto de gendermaps o esquemas de género que engloba códigos de masculinidad, feminidad y androgínia en el cerebro. Estos mapas se establecerían precozmente en la vida y estaría altamente influenciados por las hormonas durante el embarazo (Gastó, 2006).

Robert Stoller, en su libro "Sex and Gender" en 1968, analiza variantes de la sexualidad humana desde la teoría psicoanalítica. Describe el Transexualismo como la convicción de un sujeto, biológicamente normal, de pertenecer al otro sexo. Stoller trata de determinar el diagnóstico de transexualismo, diferenciándolo de otros trastornos como el travestismo o la homosexualidad en los que, a diferencia del transexual, la persona se sentiría perteneciente a su sexo asignado, y gozaría con sus órganos sexuales (Aguilar, 2008; De la Hermosa-Lorenci, 2013).

Finalmente, Ray Blanchard en 1989 sugiere, el término “autoginefília" como la propensión a ser activo sexualmente pensando que uno mismo (un varón) es una mujer. Esta definición sugiere desde la perspectiva psicopatológica, una posible alteración o profunda variación psicológica del sentido de la identidad, tanto de la identidad corporal (genital) como de la identidad mental (de la idea del propio género) (Gastó, 2006).

En la tabla 1 se sintetizan los autores que construyeron el modelo médico moderno de la discordancia de género desde mediados del siglo XIX hasta la primera mitad del siglo XX.

Tabla 1. Autores, conceptos y año relacionados con la discordancia de género

\begin{tabular}{|c|c|c|}
\hline Autor & Concepto & Año \\
\hline Ulrisch & Uranismo & 1864 \\
\hline Kertbeny & Homosexual & 1868 \\
\hline Westphal & Sentimientos sexuales contrarios & 1869 \\
\hline Krafft-Ebing & Metamorphosis sexualis paranoica & 1894 \\
\hline
\end{tabular}

Revista del Laboratorio Iberoamericano para el Estudio Sociohistórico de las Sexualidades https://doi.org/10.46661/relies.5212 


\begin{tabular}{|c|c|c|}
\hline Hirschfeld & Travestismo & 1910 \\
\hline Ellis & Inversión sexual estética/eonismo & 1913 \\
\hline Marcuse & inversión psicosexual & 1916 \\
\hline Hoyer & Cirugía anatómica Lili Elbe & 1933 \\
\hline Cauldwell & Transexual & 1949 \\
\hline Benjamin & Divulgación internacional de transexual y travesti & 1953 \\
\hline Stoller & Transexual como convicción de identidad & 1968 \\
\hline Money & Identidad de género y reasignación de género & 1969 \\
\hline Blanchard & Autoginefília & 1989 \\
\hline
\end{tabular}

Fuente: Elaboración propia

A partir de la década de los años 80's con los antecedentes médicos se generó una protocolización de la transexualidad para ser diagnosticada y tratada desde diversos campos de la medicina internacional.

El diagnóstico de "Transexualismo" aparece por primera vez en la Clasificación Internacional de las Enfermedades (CIE-9) de la Organización Mundial de la Salud (OMS) en 1978 y en la nomenclatura oficial Manual Diagnóstico y Estadístico de los Trastornos Mentales (DSM) de la Asociación Psiquiátrica Americana (APA) en 1980 (DSM-III).

En la CIE-9 (ver tabla 2), el transexualismo se ubicaba en la sección correspondiente a "Desviaciones y Trastornos Sexuales", dentro de los trastornos neuróticos, trastornos de la personalidad y otros trastornos mentales no psicóticos (Missé y Coll-Planas, 2010, López, 2018).

Al igual que en la DSM-III, todos los trastornos sexuales están agrupados conjuntamente, así mismo los divide en transexualidad y perturbaciones de la identidad psicosexual (Trastorno de la Identidad Sexual en la Infancia en el DSM-III). El transexualismo también estaría al mismo nivel que las parafilias y las disfunciones sexuales. El Transexualismo estaría definido como: "Desviación sexual centrada en la creencia fija de que los caracteres sexuales externos no son los que corresponden a la persona. La conducta resultante se dirige ya sea hacia el cambio de los órganos sexuales por medio de operación quirúrgica o hacia el ocultamiento completo del sexo aparente adoptando el vestido y los modales del sexo opuesto". Excluye el transvestismo "desviación sexual en que se obtiene placer sexual usando vestidos del sexo opuesto". Describe lo que en las clasificaciones actuales sería el transvestimo fetichista que se incluiría dentro de las parafilias y no dentro de los trastornos de la identidad de género, donde si se recogiese el transvestismo no fetichista (Fernández y García-Vega, 2012).

Tabla 2. Incorporación de la transexualidad

como trastorno médico-psiquiátrico de 1948 a 1980

\begin{tabular}{|c|c|l|}
\hline CIE-6 & 1948 & $\begin{array}{l}\text { Introducen el capítulo V dedicado a los trastornos mentales. Las } \\
\text { desviaciones sexuales se incluyen en los trastornos de personalidad y } \\
\text { los casos de transexualismo se contemplarían en este apartado. }\end{array}$ \\
\hline CIE-7 & 1955 & Sin variaciones respecto al CIE-6 \\
\hline DSM-I & 1952 & $\begin{array}{l}\text { Las desviaciones sexuales también están dentro de los trastornos de la } \\
\text { personalidad y coloca a la homosexualidad el mismo nivel que las } \\
\text { perversiones sexuales. }\end{array}$ \\
\hline
\end{tabular}




\begin{tabular}{|c|c|l|}
\hline CIE-8 & 1966 & $\begin{array}{l}\text { Aparece el diagnóstico de transvestismo que junto a la homosexualidad } \\
\text { continúan dentro de las desviaciones sexuales, y al mismo nivel que las } \\
\text { parafilias. }\end{array}$ \\
\hline DSM-II & 1968 & $\begin{array}{l}\text { Los casos de transexualismo continúan contemplándose como } \\
\text { desviaciones sexuales dentro de los trastornos de orientación sexual o } \\
\text { del transvestismo. }\end{array}$ \\
\hline Friterios & 1972 & $\begin{array}{l}\text { Por primera vez en una clasificación, el diagnóstico de transexualismo } \\
\text { debuta como una de las 15 categorías diagnósticas de mayor incidencia } \\
\text { clínica }\end{array}$ \\
\hline RDC & 1975 & $\begin{array}{l}\text { No mencionan explícitamente al transexualismo, pudiéndose incluir en } \\
\text { la categoría de "otros trastornos psiquiátricos" }\end{array}$ \\
\hline CIE-9 & 1978 & $\begin{array}{l}\text { El diagnostico de transexualismo aparece por primera vez en una } \\
\text { clasificación internacional. Estaría ubicado al mismo nivel que las } \\
\text { parafilias y las disfunciones sexuales y todo ello dentro de Desviaciones } \\
\text { y Trastornos sexuales }\end{array}$ \\
\hline DSM-III & 1980 & $\begin{array}{l}\text { Aparece el diagnóstico de transexualismo en la nomenclatura oficial de } \\
\text { la Asociación Psiquiátrica Americana. Añade un nuevo apartado, el de } \\
\text { los trastornos de la identidad sexual, donde se incluyen el } \\
\text { transexualismo y los trastornos de la identidad sexual en la infancia. }\end{array}$ \\
\hline
\end{tabular}

Fuete: Fernández y García-Vega, 2012.

En 1994 (ver tabla 3) la cuarta edición del Manual Diagnóstico y Estadístico de los Trastornos Mentales (DSM-IV) introduce cambios importantes. Mientras que la CIE-10 mantiene el término transexualismo y define tres trastornos diferentes, el DSM-IV, reemplaza el nombre de transexualismo por el de trastorno de la identidad de género (F64.x) y recoge en esta única categoría, los tres trastornos diferentes de la CIE-10. Debido a lo controvertido del DSM-III-R de incluir los trastornos de la identidad de género entre los trastornos de inicio en la infancia y adolescencia, el DSM-IV vuelve a agrupar estos trastornos con las parafilias y las disfunciones sexuales en una única categoría que pasa a denominarse "Trastornos Sexuales y de la Identidad de Género". En cuanto a las categorías diagnósticas consideradas dentro de los trastornos de la identidad de género, el DSM-IV elimina la diferenciación en función de la presencia o no de transexualismo, manteniendo únicamente una diferenciación en función de la edad del individuo (Missé y Coll-Planas, 2010; Fernández y García-Vega, 2012).

Tabla 3. Evolución de la transexualidad como trastorno médico-psiquiátrico

y su diagnóstico diferencial de 1987 a 1994

\begin{tabular}{|c|c|l|}
\hline DSM-III-R & 1987 & $\begin{array}{l}\text { Distingue los Trastornos de la Identidad de Género (TIG) de los } \\
\text { trastornos sexuales. Incluye los TIG en la sección correspondiente a } \\
\text { los Trastornos de inicio en la infancia, niñez o la adolescencia. }\end{array}$ \\
$\begin{array}{l}\text { Añade el Trastorno de la Identidad de Género en la Adolescencia o en } \\
\text { la vida Adulta, no transexual (TISAANT) } \\
\text { El diagnóstico no ha de hacerse en aquellos casos en os que el sujeto } \\
\text { presenta esquizofrenia con ideas delirantes de pertenecer a otro sexo } \\
\text { o en los que se da hermafroditismo. }\end{array}$ \\
\hline
\end{tabular}




\begin{tabular}{|c|c|l|}
\hline CIE-10 & 1992 & $\begin{array}{l}\text { Los trastornos de la identidad de género son un grupo independiente } \\
\text { de los trastornos de la inclinación sexual y de las disfunciones } \\
\text { sexuales. } \\
\text { Dentro de los trastornos de la identidad de género considera: e } \\
\text { transexualismo no fetichista y el trastorno de la identidad de género } \\
\text { en la infancia. } \\
\text { El diagnóstico no debe hacerse si es un síntoma de otro trastorno } \\
\text { mental como esquizofrenia acompañar cualquier anomalía } \\
\text { intersexual, genética o de los cromosomas sexuales. }\end{array}$ \\
\hline DSM-IV & 1994 & $\begin{array}{l}\text { Reemplaza el termino Transexualismo por el Trastorno de la } \\
\text { Identidad de Género. Vuelve a agrupar los TIG con las parafilias y las } \\
\text { disfunciones sexuales dentro de la categoría "Trastornos Sexuales y } \\
\text { de la Identidad de Género" } \\
\text { Incluye el apartado de Trastornos de la Identidad de Género no no } \\
\text { especificado para las personas que no cumplen todos los criterios (por } \\
\text { ejemplo, el travestismo no fetichista). } \\
\text { Hace alusión a la orientación de la persona con TIG atendiendo al } \\
\text { sexo de la persona por la que se siente atraído. } \\
\text { No introduce en los criterios diagnósticos que la identidad transexual } \\
\text { no debe ser síntoma de otro trastorno mental como la esquizofrenia. } \\
\text { Este tema lo desarrolla en el diagnóstico diferencial. }\end{array}$ \\
\hline
\end{tabular}

Fuente: Fernández y García-Vega, 2012.

A mediados del 2019 La Clasificación Internacional de Enfermedades (CIE-10) de la OMS fue revisada por un grupo de trabajo de expertos quienes tuvieron por objetivos centrales:

1. La despatologización y desestigmatización de las personas denominadas "transgénero"; y

2. Posibilitar el tratamiento y servicios de salud accesibles y de calidad para las personas que así lo requieran.

En dicha revisión se propone el cambio de nombre y la reconceptualización de estas categorías, incluyendo:

1. La modificación de la categoría CIE-10 F64.0 Transexualismo por "Gender Incongruence of Adolescence and Adulthood" (Discordancia de Género en la Adolescencia y Adultez), caracterizándole como "una incongruencia marcada y persistente entre la experiencia de género del individuo y el sexo asignado" durante la vida adulta, y

2. La modificación de la categoría CIE-10 F64.2 Trastorno de Identidad de Género en la Infancia por "Gender Incongruence of Childhood" (Discordancia de Género en la Infancia), caracterizándole como "una incongruencia marcada y persistente entre la experiencia/expresión de género individual y el sexo asignado en infantes pre-puberales". 
El cambio de términos (de "Identity" o Identidad a "Incongruence") tuvo el objetivo de disminuir el estigma asociado enfocándose menos en el estado mental implicado; sin embargo, la traducción literal al español "Incongruencia" podría no ser la más adecuada para estos propósitos; por lo que se ha propuesto utilizar el término castellano "Discordancia" (Robles y Ayuso-Mateo, 2019:66).

\section{4,2 Lo que han aportado las ciencias sociales}

Por varios siglos se asumió que los postulados modernos de las ciencias naturales y médicas obedecían a una ontología natural y a una epistemología objetiva. Sin embargo, los filósofos de la ciencia emplean el término 'reificación' para despejar las presuposiciones que sostienen a sus modelos, explicaciones y teorías con el afán de revelar la parcialidad de estas y su capacidad de invisibilizar descripciones alternativas de un mismo fenómeno que bien pueden resultar mucho más enriquecedoras. Así, por ejemplo, se considera que la naturalización de la raza, el género o la orientación sexual pasan por alto el proceso histórico, social y cultural que llevó a que dichos conceptos surgieran y terminaran por convertirse en identidades que diversos seres humanos han retomado (Valadez-Blanco y McManus, 2014).

A comienzos de los años noventa, aparece en los Estados Unidos una perspectiva novedosa en el campo de los estudios de género: la teoría queer. Para Gros (2016), este enfoque teórico-político pone en cuestión el carácter "natural" - $-\mathrm{y}$, por tanto, inevitable- de la llamada (cis) heteronormatividad: la matriz binaria según la cual se asignan, clasifican y regulan las identidades de género en las sociedades occidentales. Para la teoría queer, lejos de estar inscrita en la complexión ontológica del mundo o fijada en la constitución biológica de los seres humanos, esta matriz es una construcción sociohistórica. En la tarea de descentrar y desmontar el régimen sexual dominante en Occidente, los teóricos queer recurren a procedimientos críticos que se inspiran en la deconstrucción posestructuralista de la metafísica occidental.

La premisa fundamental de la teoría queer consiste en la desontologización de las identidades de género, que solo se puede lograr a través de la visibilización del carácter construido y contingente de estas. Por lo que el constructivismo se muestra como el antídoto para el esencialismo y sus consecuencias violentas. La teoría queer se compromete con la idea de que el género es un constructo sociohistórico (Butler, 2007; De Lauretis, 1987; Sedwick, 1990; Preciado, 2008).

De esta forma, la categoría de género desde las ciencias sociales surge como herramienta de reificación que analiza y cuestiona los presupuestos del modelo binario y heterosexual "natural" en los que se ha basado la organización social. En las discusiones académicas sobre el género, existe controversia constante entre dos visiones presentes en distintos ámbitos sociales: una esencialista, que entiende al género como una propiedad inherente a los seres humanos, y la otra, como una categoría analítica que refiere a un orden social. Cuando se parte de una visión esencialista, no suele hacerse ninguna diferencia entre sexo y género, ambos se utilizan como marcadores biológicos de la diferencia entre hombres y mujeres. Tampoco se reflexiona sobre el uso del "ser" y las posibilidades de que esta característica de las personas, el género, tenga carácter social y no natural. $\mathrm{O}$ al menos una mezcla de ambas cosas. El "ser mujer" o "ser hombre", "ser femenina" o "ser masculino", se percibe en términos generales, como algo natural y fundamental en la vida de las personas, como algo vinculado al cuerpo, que se concibe en sí mismo como incuestionable. Como una esencia. En este sentido, mujer y hombre se utilizan como categorías ontológicas. Las correspondencias entre los elementos corporales y las categorías identitarias también son naturalizadas: vulva-hembra-mujer-femenina, pene/testículos-macho-hombre-masculino, así como su relación con el deseo erótico, que se asume, es heterosexual por naturaleza (Martinez, 2015).

Por tanto, el género se puede entender como una división de los sexos socialmente impuesta. Es un producto de las relaciones sociales de sexualidad. Los sistemas de parentesco se basan en el

Revista del Laboratorio Iberoamericano para el Estudio Sociohistórico de las Sexualidades https://doi.org/10.46661/relies.5212 
matrimonio; en consecuencia, transforman a machos y hembras en hombres y mujeres, cada uno una mitad incompleta que sólo puede sentirse entera cuando se une con la otra (Rubin, 1986:114).

Butler (2007), añade que el género es el resultado de un proceso, conformado por prácticas regulatorias complementarias, mediante el cual las personas, miembros de una sociedad estructurada con base en un modelo heteronormativo, reciben e inscriben significados culturales en sus cuerpos. Además, propone entender al género como un acto performativo, es decir, que constituye la identidad que se supone que es. El género se hace y se repite. No es un acto único, como si fuera una actuación calculada, sino una repetición y un ritual que consigue su efecto a través de la naturalización de un cuerpo, entendido hasta cierto punto, como una duración temporal, sostenida culturalmente.

Una de las consecuencias más significativas del impacto de la reificación del modelo heteronormativo y binario de la sexualidad a través del análisis de género lo describe Scott (2008:11), cuando en la Cuarta Conferencia Mundial sobre las Mujeres celebrada en Beijing, China, en el otoño de 1995, el término género levantó polémicas. Scott relata que, en las semanas siguientes a la celebración de la conferencia, un subcomité de la Cámara de Representantes de los Estados Unidos llevó a cabo audiencias en donde los delegados y representantes republicanos de los grupos provida en el Congreso señalaron las consecuencias subversivas del término género. Los conferenciantes advirtieron que la moralidad y los valores familiares estaban siendo atacados por quienes creían que debían existir como mínimo cinco géneros (hombres, mujeres, homosexuales, bisexuales y transexuales). Insistieron en que el Programa de las Naciones Unidas para la Conferencia de Beijing había sido secuestrado por "las feministas del género", quienes creen que todo lo que consideramos natural, como el ser mujer y el ser hombre, la feminidad y la masculinidad, la maternidad y la paternidad, la heterosexualidad, el matrimonio y la familia son, en realidad, conceptos creados culturalmente, generados por los hombres para oprimir a las mujeres.

Este indeterminismo biológico se exponencia con las identidades trans en las que no importa la biología. Hay un desprendimiento absoluto entre cuerpos e identidades, si entendemos los cuerpos sobre la base de las asociaciones efectuadas en las categorías sexuales. En las identidades trans, cualquiera sea el cuerpo, lo que importa es la identidad que es independiente de toda biología. Las identidades trans implican una ruptura casi absoluta con el biologicismo (Lamm, 2018).

Así, desde las aportaciones de las ciencias sociales sobre el género como categoría normativa y de análisis, se comenzaron a hacer sonar las voces de quienes encarnaban la "patología" definida como transexual desde la medicina, así como aquellas voces de personas que no se identificaban con esta categoría, pero aun así recuperan el vocablo "trans" para describir su experiencia de no identificación con el género y/o el sexo asignado corporalmente, y aquellas otras voces de quienes buscan salir del binarismo de género para dar paso a una identidad fluida, se construye la Red Internacional por la Despatologización de las Identidades Trans (RIDIT), en un intento por deshacer el marco conceptual que coloca a sus cuerpos y expresiones de género como patologías (López, 2018).

Los objetivos de la red son:

1. Retirada de la categoría de "disforia de género" / "trastornos de la identidad de género" de los manuales internacionales de diagnóstico (sus próximas versiones DSM-5 y CIE-11).

2. Abolición de los tratamientos de normalización binaria a personas intersex.

3. El libre acceso a los tratamientos hormonales y a las cirugías (sin tutela psiquiátrica). 
4. La cobertura pública de la atención sanitaria trans- específica (acompañamiento terapéutico voluntario, seguimiento ginecológico-urológico, tratamientos hormonales, cirugías).

5. La lucha contra la transfobia: el trabajo para la formación educativa y la inserción social y laboral de las personas trans, así como la visibilización y denuncia de todo tipo de transfobia institucional o social.

De esta forma, lo que inició como un movimiento social de protesta pública focalizada ha crecido hasta transformarse en una red internacional que continúa año con año convocando acciones bajo estos objetivos. La recepción de su convocatoria en todo el mundo ha demostrado que existe un apoyo creciente a la demanda por la despatologización. En el caso de México, éste ha participado en la campaña desde 2010, registrando hasta 2017 la participación de 27 organizaciones aliadas. Ellas representan a activistas de diversos estados, como Baja California, Guanajuato, Jalisco, Chiapas, Querétaro, Monterrey, San Luis Potosí, Ciudad de México y Puebla (López ,2018).

La lucha política como camino para el reconocimiento de la identidad es una de las bases para el activismo trans en la búsqueda del goce efectivo de los derechos humanos, particularmente la libertad (El libre desarrollo de la personalidad, la libertad de pensamiento, acción, circulación y elección) y el derecho a la identidad y al nombre. Estos, leídos como derechos personalísimos cuyo ejercicio debe ser exigido particularmente para las personas trans en clave de igualdad (Adrián, 2008).

De acuerdo con Lamm (2018:234), podemos decir que las personas "trans" son aquellas personas cuya identidad y/o expresión de género no se corresponde con las normas y expectativas sociales tradicionalmente asociadas con el sexo asignado al nacer. Mientras que las personas "cis" o "cisgénero" son personas cuya identidad y/o expresión de género se corresponde con su sexo asignado al nacer. "Trans" es entonces un término paragua utilizado para describir las diferentes variantes de la identidad de género, y comprende a todas las personas cuyo común denominador es que se identifican con un género diferente del que les fuera asignado al nacer, independientemente de intervenciones quirúrgicas o tratamientos médicos.

La patologización y criminalización de la diversidad sexual entendida esta como las prácticas e identidades abyectas contrarias al sistema cis-heteronormativo y al binarismo sexual, construyó en el siglo XIX y XX sujetos enfermos y criminales necesitados de tratamiento y/o castigo para los cuales no había acceso a derechos civiles, políticos o económicos. A partir de la reificación desnaturalizadora de dicho sistema a través, por una parte, de los estudios sociales de género como categoría normativa y de análisis, y por otra de los movimientos sociales de minorías sexuales, se ha logrado repensar la legitimidad de identidades y prácticas sexuales abriendo la posibilidad de existencias diversas que puedan gozar de más derechos y ciudadanías plenas (López, 2018).

\section{5 ¿Hay derechos para personas que viven discordancia de género?}

Entre los antecedentes más remotos que plantean el tema de los derechos humanos de las personas trans -aunque cabe aclarar que, realizado entre particulares, sin ningún valor resolutivo vinculante, está la Declaración Internacional de los Derechos de Género, la cual fue aprobada y adoptada el 28 de agosto de 1993 por las y los asistentes a la Segunda Conferencia Internacional sobre Legislación de Transgénero y Política de Empleo en Houston, Texas. Entre los derechos considerados en esa Declaración se ubican: el derecho de las personas a reivindicar la identidad de género, el derecho a la libre expresión de la identidad y el papel del género, el derecho a determinar y 
modificar el propio cuerpo, y el derecho a un servicio médico competente y profesional (Rueda, 2015).

En 2006, con los Principios de Yogyakarta, se compilaron e hicieron explícitas las obligaciones de derechos humanos contraídas por los Estados en relación con la orientación sexual y la identidad de género en tratados internacionales.

En ese contexto, el 1 de diciembre de 2006, a nombre de 54 estados de Europa, América, Asia y el Pacífico -entre los que se encontraba también México-, Noruega presentó al Consejo de Derechos Humanos de las Naciones Unidas una declaración sobre violaciones a los derechos humanos relacionadas con la orientación sexual y la identidad de género (Rueda, 2015).

Así mismo, la Organización de los Estados Americanos (OEA, 2008) adoptó, a través de su Asamblea General, la resolución propuesta por Brasil sobre derechos humanos, orientación sexual e identidad de género. Asimismo, es de destacar el documento presentado por la Comisión de Asuntos Jurídicos y Políticos del Consejo Permanente de la OEA (OEA, 2012), el 23 de abril de 2012, denominado Orientación sexual, identidad de género y expresión de género: algunos términos y estándares relevantes -elaborado por la Comisión Interamericana de Derechos Humanos (CIDH), en cumplimiento a la resolución de junio de 2008-, y que incluyó, además de la identidad de género, la expresión de género.

El 18 de diciembre de 2008, por iniciativa de Francia y con el apoyo de la Unión Europea, se presentó ante el pleno de la Asamblea General de las Naciones Unidas (ONU, 2008) una declaración sobre derechos humanos, orientación sexual e identidad de género, la cual contó con el respaldo de 66 países de los 192 que conforman la comunidad internacional, México entre ellos.

En México, la Ley Federal para Prevenir y Eliminar la Discriminación (LFPED) aprobada el 29 de abril de 2003, y publicada en el Diario Oficial de la Federación (DOF) el 11 de junio del mismo año crea el Consejo Nacional para Prevenir La Discriminación, CONAPRED. El Consejo es la institución rectora para promover políticas y medidas tendientes a contribuir al desarrollo cultural y social y avanzar en la inclusión social y garantizar el derecho a la igualdad, que es el primero de los derechos fundamentales en la Constitución Federal.

En materia de política pública, en abril de 2014 se expidió un decreto por el cual se anunció la entrada en vigor del Programa Nacional de Derechos Humanos 2014-2018 (PNDH, 2014) -el tercero de los que se han elaborado y aplicado en nuestro país- y del Programa Nacional para la Igualdad y No Discriminación 2014-2018 (PRONAID, 2014)

En el PNDH vigente se incluyó la línea de acción 3.2.3 (Objetivo 3. Garantizar el ejercicio y

goce de los derechos humanos y de la Estrategia 3.2. Responder a las problemáticas de derechos humanos de personas y grupos específicos) que habla de "impulsar una cultura de respeto de los derechos de las personas LGBTTTI".

En el PNDH 2008-2012, durante la pasada administración, se incluyeron dos líneas de acción que hacen referencia a la población LGBTTTI, una de ellas específicamente a favor del reconocimiento de la población trans.

Por su parte, en el PRONAID -Objetivo 5. Fortalecer el cambio cultural en favor de la igualdad, diversidad, inclusión y no discriminación con participación ciudadana, Estrategia

5.2. Impulsar acciones contra la discriminación por orientación sexual e identidad de género- se integran seis líneas de acción que se plantean garantizar y promover la no discriminación por orientación sexual e identidad de género. Y en la Estrategia 5.2.6 se menciona el hecho de "conjuntar esfuerzos para llevar a cabo campañas para combatir la homofobia y la transfobia". 
Para la OMS (2010) los derechos sexuales abarcan los derechos humanos que ya se reconocen en las leyes nacionales, en los documentos internacionales de derechos humanos y en otras declaraciones de consenso. Comprenden el derecho de todas las personas para que, libres de coacción, discriminación y violencia, puedan:

- Alcanzar el nivel más alto posible de salud sexual, lo que comprende el acceso a servicios de atención de salud sexual y reproductiva;

- Buscar, recibir y divulgar información con relación a la sexualidad;

- Recibir educación de la sexualidad;

- Respeto de su integridad física;

- Elegir su pareja;

- Decidir si se quiere ser sexualmente activo o no;

- Tener relaciones sexuales consensuales;

- Contraer matrimonio consensual;

- Decidir si la persona quiere tener hijos o no, y cuándo quiere tenerlos; y

- Llevar una vida sexual satisfactoria, segura y placentera.

Estos y otros ordenamientos internacionales ponen de manifiesto que dentro de las NacionesEstado existen sujetos de derechos y dentro de estos derechos, los que hacen referencia específicamente a la sexualidad y a la salud de esta. Así, las políticas públicas y los sistemas socializadores de las mismas como el sistema educativo, político, científico, familiar, económico, laboral, etc. deberán mantener un marco de referencia relacionado con los derechos humanos en general y los derechos sexuales en particular (Vilchis, 2017).

En este sentido, existen todavía muchos desafíos que atender en términos de violencia, exclusión, marginación, discriminación, invisibilización, explotación, coerción y opresión de grupos en situación de vulnerabilidad por razones de identidad de género, raza, etnia, clase social, nivel educativo, edad, discapacidad, condiciones de salud/enfermedad, entre otros. Quedando de manifiesto que las diferencias (rarezas) interpretadas como desventaja siguen operando en el imaginario colectivo como rechazo a la diversidad. En ese contexto de complejidades socioculturales, las teorías post-feministas cuestionan, deconstruyen, decolonizan e intentan transformar el orden, el estatus, la normalidad y el esencialismo de las categorías "naturaleza" y "naturaleza humana binaria", que han sido medulares en el establecimiento de narrativas, discursos e imaginarios culturales opresores, cultural y estructuralmente violentos (CONAPRED, 2017).

\section{6 ¿Qué significa ser ciudadana/o?}

Para Raupp (2004), la democracia y la ciudadanía son ideas centrales en los diversos movimientos sociales contemporáneos. Mediante su articulación, una variada gama de reivindicaciones ha logrado avances importantes, incluyendo demandas de diversos sectores de la vida individual y colectiva. Uno de los efectos de esta dinámica ha sido la comprensión cada vez más difundida, de las múltiples dimensiones requeridas para la construcción de una sociedad democrática, como demuestran las demandas de inclusión social, económica, política y cultural. Estas dimensiones marcan también una ampliación del concepto de ciudadanía, ya que éste tradicionalmente se asociaba sólo con el estatus jurídico adquirido en virtud de la pertenencia nacional.

No se debe perder de vista que la noción de ciudadanía está ligada a las relaciones de poder y formación de significados sociales. La constitución del ciudadano/a tiene lugar mediante una serie de recursos simbólicos que permiten la participación en los múltiples planos de la vida social. Lo cual exige tanto eliminar las condiciones ideológicas y materiales que promueven varias formas de 
subordinación y marginalidad (de género, sexualidad, clase, raza), como potenciar los saberes que se poseen y adquirir otros nuevos para actuar en los espacios privados y públicos, para reconocer las necesidades de grupos sociales diversos y para negociar las relaciones en los diversos ámbitos (Di Marco, 2012).

Por lo que la ciudadanía plena sigue siendo, hoy día, un problema del modelo de democracia, pues los sujetos no se involucran o se involucran poco en los intereses de su colectividad; no obstante, estas conductas no se explican a partir de actitudes de apatía. Y es que la calidad de ciudadanía no es un estatus político-civil que se adquiere con el sólo hecho de llegar a la mayoría de edad, sino que es algo que se construye y potencializa en el tiempo, y que, sin lugar a duda, está atravesado por las condiciones de historia de vida y estructurales como pobreza, marginalidad, discriminación, exclusión, violencia, entre otras muchas (López y Serrato, 2018).

Así, más que un proyecto completado y estable que define las relaciones entre el Estado y sus sujetos, la ciudadanía es siempre contenciosa; su consolidación no es un accidente histórico, sino el resultado de luchas sociales sobre el establecimiento de las condiciones necesarias que permitan el derecho a la participación política. De esta manera, la condición de ciudadanía está vinculada con las luchas sociales que le han dado forma. Es importante hacer énfasis en la noción de luchas sociales como el motor principal de la ciudadanía, lo cual sugiere que siempre está en proceso de ser construida y reconstruida, negociada y renegociada, formada y reformada; esto quiere decir que se abandona la concepción pasiva y estática, en favor de una más dinámica y activa (Susen, 2010).

Shepard (2004) añade que la ciudadanía tiene dos elementos principales: el primero es la participación ciudadana, en que todos los ciudadanos y ciudadanas tienen una voz en las políticas y programas que afectan su vida. Es el principio básico de las democracias. Aplicando este principio a la sexualidad, entonces la ciudadanía sexual será el tener voz y voto en las políticas y programas que afectan el ejercicio autónomo de la sexualidad y la salud sexual. El segundo elemento tiene relación con el concepto de ser "sujeto de derechos", es decir, de vivir en un Estado que respeta y protege los derechos humanos de las y los ciudadanos y que asume la responsabilidad de hacer cumplir estos derechos. Los derechos que tienen más relevancia para la sexualidad son: el derecho a la integridad física, a la salud, a la no-discriminación, a la sobrevivencia y desarrollo, a la libertad de expresión; y el derecho reproductivo de decidir libremente sobre número y espaciamiento de los hijos.

Al mismo tiempo, Di Marco (2012) afirma que la ciudadanía está relacionada a los espacios de socialización donde se forman las identidades de sujetos que tienen cuerpos, deseos, intereses y necesidades diferentes, que participan como seres situados en el mundo, a partir de su experiencia corporal y emocional, lo cual trae como consecuencia que la noción de ciudadanía no puede ser considerada en abstracto, ya que los espacios de socialización van marcando identidades basadas mayormente en el modelo cisheterosexual, que condiciona el ejercicio de la ciudadanía para los y las que no "encajan" en esos modelos socialmente construidos.

\subsection{Ser un/a ciudadana/o diferente}

Los teóricos de la ciudadanía sexual enfatizan que lo sexual ha jugado un papel clave en cómo los gobiernos occidentales construyen los derechos de ciudadanía. Las feministas han señalado durante mucho tiempo que los derechos de ciudadanía occidental se han desarrollado alrededor de la concepción del ciudadano como el jefe del hogar masculino donde las mujeres estaban subordinadas. En otras palabras, los derechos de los ciudadanos y sus beneficios se construyeron de una manera que asumía que el ciudadano era heterosexual. Fue una forma de ciudadanía sexual heteronormativa. Por lo tanto, el concepto de ciudadanía sexual es particularmente útil para llamar la atención sobre la naturaleza heteronormativa de la forma en que muchos derechos de ciudadanía 
fueron construidos originalmente y al explicar por qué obtener tales derechos a veces puede tener consecuencias normalizadoras dado su origen en un modelo heterosexual (Johnson, 2017).

Prevalece la creencia científica de que, al paso de los años, la noción de ciudadanía se perfecciona y se vuelve más incluyente; no obstante, en el modelo normativo de democracia prevalecen las ciudadanías uniformes y heteronormadas, con lo que no se da cabida a lo diverso. Este paradigma, entonces, desconoce, entre otras ciudadanías, a las sexuadas, con lo que se les niega el pleno ejercicio de sus derechos. Las personas de la diversidad sexual no sólo están en la lucha del goce de derechos y obligaciones como los ciudadanos que son reconocidos por el modelo normativo, sino también dando la batalla en la reconfiguración sociocultural (López y Serrato, 2018).

Maffia (2001) argumenta que la ciudadanía sexual implica "hacer visible la condición sexuada de los ciudadanos, de lo contrario se facilita que el Estado vulnere derechos básicos. Además, la sexualización de los sujetos opera en una dinámica que exige al Estado modificar su accionar, con tal de atender las particularidades y necesidades específicas de los grupos sociales" (p. 28).

Por su parte, Richardson (2000), ha identificado tres aspectos principales de los derechos sexuales que están implicados en la ciudadanía sexual. Estos tres aspectos involucran la práctica sexual, los derechos de autodefinición e identificación y derechos adquiridos a través de instituciones sociales y políticas. Se debe tener cuenta que los problemas de ciudadanía sexual no son solo políticos en el sentido estricto que involucran al gobierno, también son económicos y sociales e incluyen los derechos de las minorías. La ciudadanía sexual está implicada en cómo la ciudadanía se concibe de manera más amplia y en formas particulares de gobierno del individuo.

La versión neoliberal capitalista de ciudadanía sexual, por ejemplo, está en parte formada por una mercantilización de la ciudadanía que pone énfasis en la elección del "estilo de vida" del consumidor. En este sentido, Evans (1993) critica la visión tradicionalista de lo sexual como algo individual, personal, privado y separado de las estructuras materiales y de las relaciones de poder, y caracteriza a los grupos sexuales minorizados como participantes de una ciudadanía, a través del consumo de mercancías sexualizadas elaboradas específicamente para ese mercado.

En México, Antonio (2017) elaboró el Índice de Reconocimiento de Derechos LGBT a nivel subnacional para identificar el estado real del reconocimiento de los derechos LGBT (a julio de 2017). Dio como valor " 1 " cuando existe el reconocimiento de derechos y "0" cuando no existe, lo que arroja un índice general donde " 8 " es el máximo de reconocimiento de derechos y " 0 " el mínimo (Ver Tabla 4).

Tabla 4. Índice de Reconocimiento de Derechos LGBT a nivel Subnacional 2017

\begin{tabular}{|l|c|c|c|c|c|c|c|c|c|}
\hline \multirow{2}{*}{ Estados / Indicadores } & \multicolumn{7}{|l|}{ 1=Si; O=No } \\
\cline { 2 - 11 } & A & B & C & D & E & F & G & H & I \\
\hline Ciudad de México & 1 & 1 & 1 & 1 & 1 & 1 & 1 & 1 & 8 \\
\hline Coahuila & 1 & 1 & 1 & 1 & 1 & 1 & 1 & 0 & 7 \\
\hline Campeche & 1 & 1 & 1 & 1 & 1 & 0 & 1 & 0 & 6 \\
\hline Colima & 1 & 1 & 1 & 1 & 1 & 1 & 0 & 0 & 6 \\
\hline Michoacán & 1 & 1 & 1 & 1 & 1 & 0 & 0 & 1 & 6 \\
\hline Quintana Roo & 1 & 1 & 0 & 1 & 0 & 1 & 0 & 0 & 4 \\
\hline
\end{tabular}

Revista del Laboratorio 


\begin{tabular}{|c|c|c|c|c|c|c|c|c|c|}
\hline Chiapas & $1 * *$ & 0 & 0 & 1 & 1 & 1 & 0 & 0 & 4 \\
\hline Chihuahua & 1 & 0 & 0 & 1 & 1 & 1 & 0 & 0 & 4 \\
\hline Nayarit & 1 & 0 & 0 & 1 & 1 & 0 & 0 & 1 & 4 \\
\hline Jalisco & $1 * *$ & 1 & 0 & 1 & 0 & 0 & 0 & 0 & 3 \\
\hline Morelos & 1 & 0 & 1 & 1 & 0 & 0 & 0 & 0 & 3 \\
\hline Durango & 0 & 0 & 0 & 1 & 1 & 1 & 0 & 0 & 3 \\
\hline Guerrero & 0 & 0 & 0 & 1 & 1 & 0 & 0 & 0 & 2 \\
\hline Puebla & $1 * *$ & 0 & 0 & 1 & 0 & 0 & 0 & 0 & 2 \\
\hline Aguascalientes & 0 & 0 & 0 & 1 & 0 & 1 & 0 & 0 & 2 \\
\hline Baja California Sur & 0 & 0 & 0 & 1 & 1 & 0 & 0 & 0 & 2 \\
\hline Hidalgo & 0 & 0 & 0 & 1 & 1 & 0 & 0 & 0 & 2 \\
\hline Zacatecas & 0 & 0 & 0 & 1 & 1 & 0 & 0 & 0 & 2 \\
\hline San Luis Potosí & 0 & 0 & 0 & 1 & 1 & 0 & 0 & 0 & 2 \\
\hline Sonora & 1 & 0 & 0 & 1 & 0 & 0 & 0 & 0 & 2 \\
\hline Tlaxcala & 0 & 0 & 0 & 1 & 0 & 1 & 0 & 0 & 2 \\
\hline Veracruz & 0 & 0 & 0 & 1 & 0 & 1 & 0 & 0 & 2 \\
\hline Yucatán & 0 & 0 & 0 & 1 & 1 & 0 & 0 & 0 & 2 \\
\hline Estado de México & 0 & 0 & 0 & 1 & 0 & 0 & 0 & 0 & 2 \\
\hline Baja California & 0 & 0 & 0 & 1 & 0 & 0 & 0 & 0 & 1 \\
\hline Guanajuato & 0 & 0 & 0 & 1 & 0 & 0 & 0 & 0 & 1 \\
\hline Nuevo León & 0 & 0 & 0 & 1 & 0 & 0 & 0 & 0 & 1 \\
\hline Oaxaca & 0 & 0 & 0 & 1 & 0 & 0 & 0 & 0 & 1 \\
\hline Querétaro & 0 & 0 & 0 & 1 & 0 & 0 & 0 & 0 & 1 \\
\hline Sinaloa & 0 & 0 & 0 & 1 & 0 & 0 & 0 & 0 & 1 \\
\hline Tabasco & 0 & 0 & 0 & 1 & 0 & 0 & 0 & 0 & 1 \\
\hline Tamaulipas & 0 & 0 & 0 & 1 & 0 & 0 & 0 & 0 & 1 \\
\hline
\end{tabular}

A: Matrimonio igualitario, B: Unión civil, C: Adopción parejas del mismo sexo, D: Despenalización, E: Leyes antidiscriminación por orientación sexual, F: Discriminación delito penal, G: Delito crimen de odio, H: Identidad de género, I: Índice de Derechos

* Si bien la SCJN ha declarado inconstitucional el restringir el matrimonio entre personas del mismo sexo, en este indicador registramos sólo el reconocimiento en las leyes estatales del matrimonio igualitario pues sigue siendo una práctica discriminatoria y diferenciada condicionar el derecho al amparo cuando en otros estados hay un trato igualitario según la ley. ${ }^{* *}$ En estos estados la SCJN declaró inconstitucional el código civil vigente, por lo cual invalidó la definición legal, aunque sigue sin existir una ley que lo regule. 
En el análisis de Antonio (2017), se detalla el no reconocimiento de los derechos sexuales que siguen siendo causa de lucha por una ciudadanía sexual justa y digna de una democracia incluyente de los colectivos de la diversidad sexual. La noción de ciudadanía sexual intenta hacer visible el desbalance de derechos existente entre los géneros, normada ésta por los patrones patriarcales y heterosexuales, que dejan en posición de subordinación a los individuos que no se ajustan a la masculinidad hegemónica (Di Marco, 2012).

Así, el contexto de expansión de la ciudadanía sexual - esto es, la reinterpretación de las sexualidades a través del lenguaje de la ciudadanía y los derechos - varía ampliamente según contextos y genealogías particulares. Desde el punto de vista de la igualdad de derechos y los ideales anti-discriminatorios, todas las luchas por los derechos LGBTTTI son indiscutiblemente legítimas. Tienen que ver con el acceso de las personas cuya sexualidad o género no se corresponden con los parámetros heteronormativos, a los derechos concebidos como universales. Se trata de su inclusión dentro de la ciudadanía, donde la ciudadanización de muchxs disidentes u "otrxs" sexuales implica un tratamiento en pie de igualdad. Este reconocimiento es en parte deudor de lo que se ha entendido como la judicialización de los reclamos LGBTTTI, es decir, la concentración de recursos en la modificación de los marcos legales existentes principalmente en función del derecho a la identidad y el respeto a la diferencia (Sabsay, 2018).

\section{2 ¿Están las personas diversas incluidas en el proyecto mexicano?}

A partir del año 2001, las políticas públicas relacionadas con la diversidad sexual han estado cada vez más presentes en la agenda de cada sexenio presidencial. Los Programas Nacionales de Desarrollo (PND) 2001 al 2024 han incorporado poco a poco la perspectiva de diversidad sexual bajo un enfoque de Derechos Humanos (Vilchis, 2017).

EI PND 2001-2006 es el primero de la alternancia política; cuando gana el Partido Acción Nacional y Vicente Fox asume la presidencia de la República. El programa tiene tres ejes y está orientado a la política de desarrollo social y humano, que se refiere a los niveles de bienestar de las personas.

En ninguno de los ejes del PND es explicita la referencia al movimiento de la diversidad sexual. Sin embargo, sí se menciona, en la sección "Compromisos por México" en la que se refiere: "La persona debe ser el objetivo de todas nuestras acciones de gobierno. Estamos comprometidos con impulsar los proyectos que permitan el crecimiento personal y colectivo de todos los mexicanos, sin soslayar su dignidad ni discriminar por género, religión, condición económica, educación, origen étnico o preferencia sexual" (p.123).

EI PND 2007-2012 bajo la presidencia de Felipe Calderón tuvo cinco ejes y en ninguno de los ejes hace referencia explícita a la diversidad sexual. Sin embargo, en las estrategias del eje uno se menciona: "Modificar el enfoque de las políticas públicas para la defensa de los derechos humanos, superando la visión que pretende únicamente restituir el goce de los mismos, para privilegiar un enfoque preventivo de la violación de estos derechos. Esta nueva orientación resulta particularmente importante en el caso de miembros de grupos vulnerables como son los niños, los adultos mayores, los discapacitados, los enfermos y cualquier otro grupo social que, por sus características, se encuentre expuesto a la violación de sus derechos humanos" (p.66).

En el PND 2013-2018 durante la presidencia de Enrique Peña Nieto la primera meta nacional hace mención directa de los derechos de las personas independientemente de su orientación sexual y en la meta tres se asienta que como la aplicación de políticas públicas para la equidad aún son deficientes se ha de considerar la inclusión para la no discriminación por orientación sexual.

El PND 2019-2024 encabezado por el presidente Andrés Manuel López Obrador incorpora la perspectiva de la diversidad sexual con enfoque de derechos humanos: "rechazamos toda forma de

Revista del Laboratorio Iberoamericano para el Estudio Sociohistórico de las Sexualidades https://doi.org/10.46661/relies.5212 
discriminación por características físicas, posición social, escolaridad, religión, idioma, cultura, lugar de origen, preferencia política e ideológica, identidad de género, orientación y preferencia sexual" (p.11). En el apartado de libertad e Igualdad, menciona: "El gobierno federal priorizará las libertades por sobre las prohibiciones, impulsará los comportamientos éticos más que las sanciones y respetará escrupulosamente la libertad de elección de todos los ciudadanos en todos los aspectos: las posturas políticas e ideológicas, las creencias religiosas, las preferencias sexuales" (p.33). En el apartado de política social: "el gobierno federal impulsará una nueva vía hacia el desarrollo para el bienestar, una vía en la que la participación de la sociedad resulta indispensable y que puede definirse con este propósito: construiremos la modernidad desde abajo, entre todos y sin excluir a nadie. Será una construcción colectiva, que incluya la vasta diversidad de posturas políticas, condiciones socioeconómicas, espiritualidades, culturas, regiones e idiomas, ocupaciones y oficios, edades e identidades y preferencias sexuales que confluye en la población actual de México" (p.46).

Estos programas no son de redistribución, ya que no plantean acabar con la injusticia económica, es decir, no se considera ninguna de las dimensiones de lucha de clase para distribuir la riqueza. por lo tanto, se sigue necesitando una reestructuración de las relaciones de producción, que se difuminen los factores de diferenciación entre los grupos, y, con esto, que se contribuya a reparar algunas formas de falta de respeto y se ejerza un pleno reconocimiento de las identidades y no sólo de manera parcial (Vilchis, 2017).

Como menciona Fish (2007), los conceptos de privacidad y heteronormatividad sirvieron para excluir a las personas de la diversidad sexual del bienestar. Además, los discursos sociales y políticos suponían que las personas LGBTTTI no experimentaban discriminación. Debido a este contexto, muchas personas han sido renuentes a revelar su orientación sexual a los profesionales y son usuarios invisibles de los servicios de salud y servicios sociales (p.224).

A continuación, se muestran algunos mapas comparativos de legislación y políticas públicas de derechos civiles de la diversidad sexual en el mundo y en México.

Figura 1. Reconocimiento legal de uniones del mismo sexo y prácticas homosexuales ilegales y restringidas en el mundo

Matrimonio entre personas del mismo sexo

Reconocimiento de matrimonios del mismo sexo realizados en otros estados o países Unión civil

Reconocimiento legal limitado 


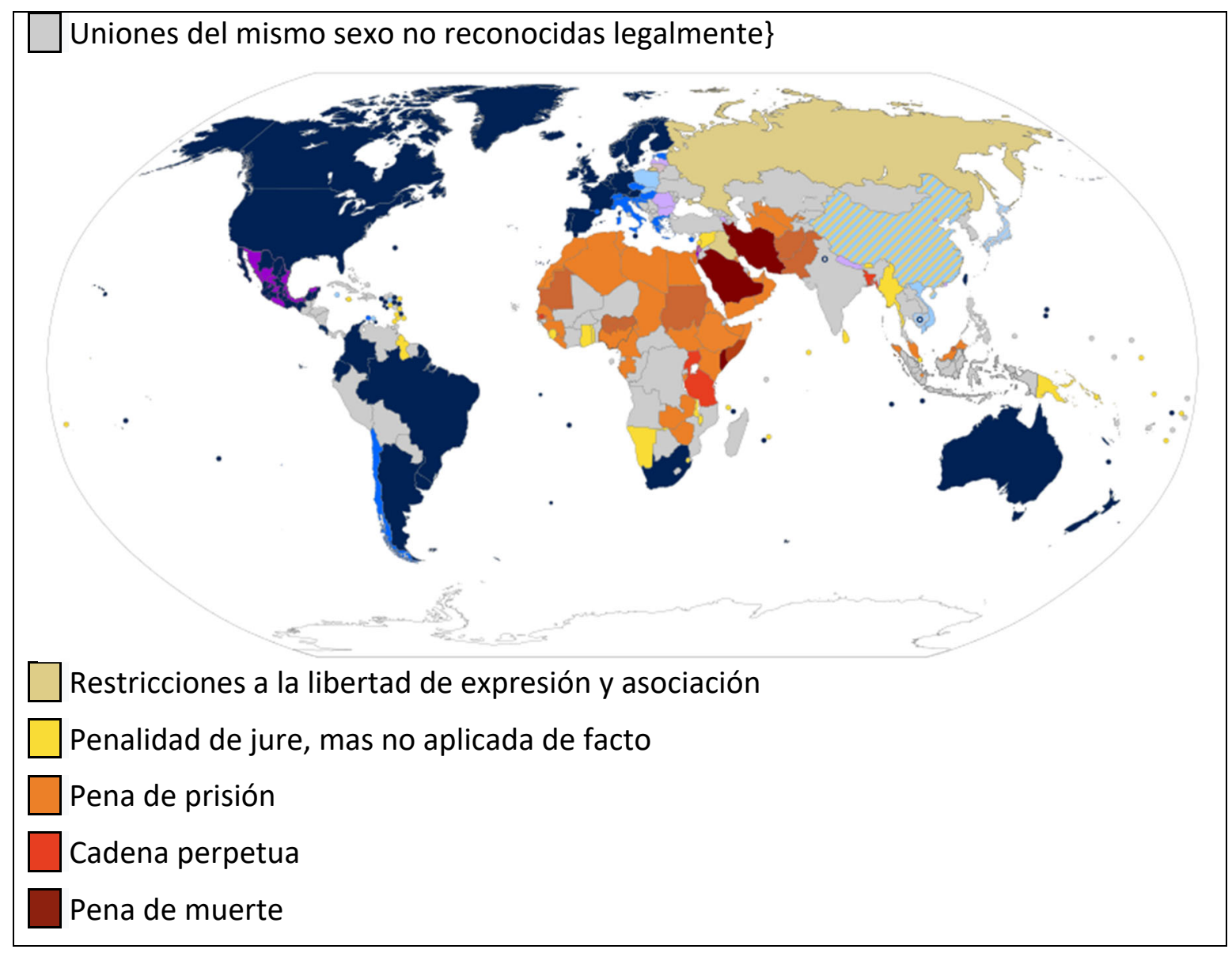

Fuente: https://es.wikipedia.org/wiki/Legislaci\%C3\%B3n_sobre_derechos_LGBT_en_el_mundo

Figura 2. Leyes mundiales relativas a la expresión de la identidad de género 


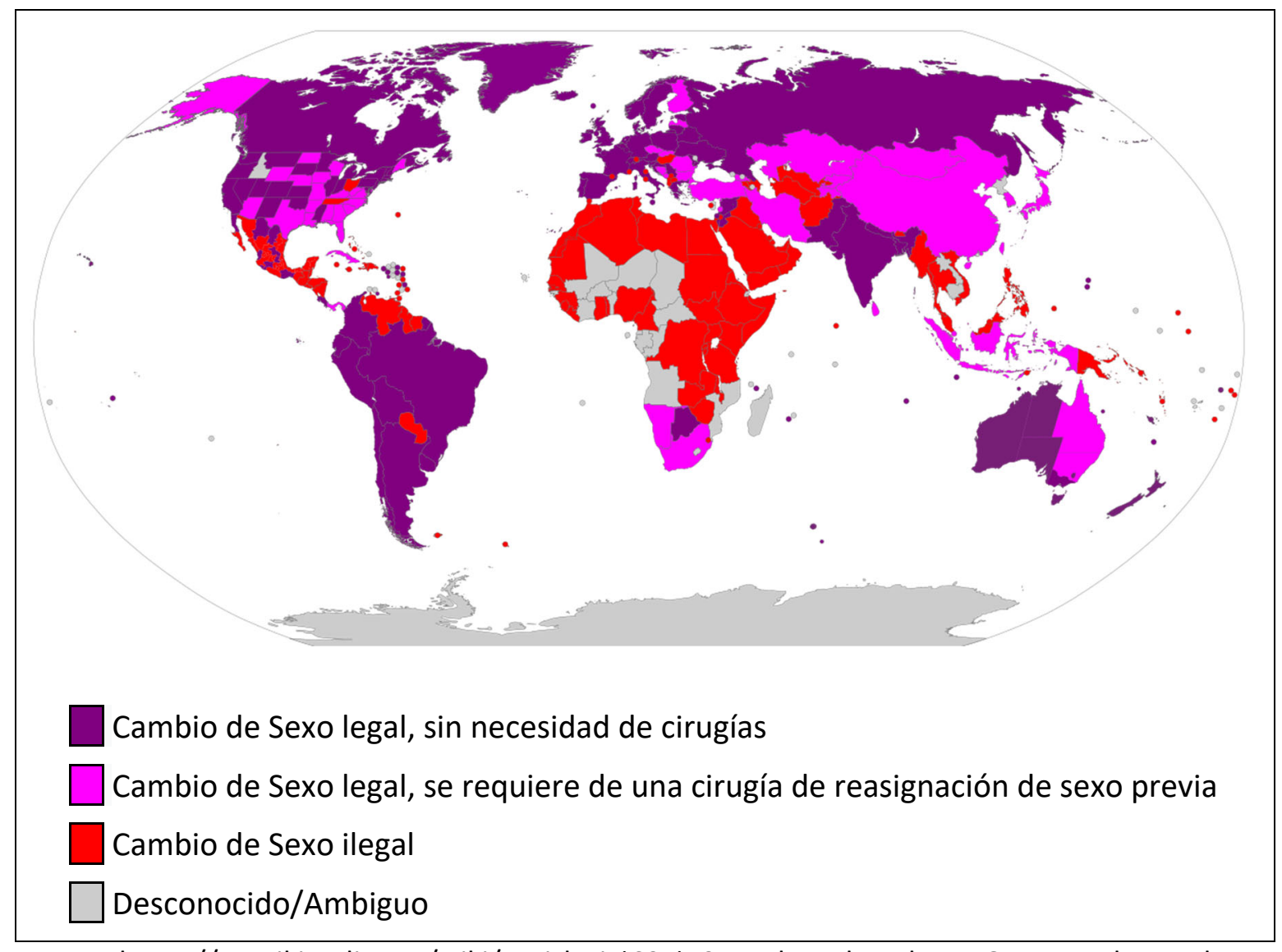

Fuente: https://es.wikipedia.org/wiki/Legislaci\%C3\%B3n_sobre_derechos_LGBT_en_el_mundo

Tabla 5. Leyes mexicanas relacionadas con la diversidad sexual en México

\begin{tabular}{|c|c|c|c|c|c|c|}
\hline $\begin{array}{l}\text { Actividad sexual } \\
\text { entre personas del } \\
\text { mismo sexo }\end{array}$ & $\begin{array}{l}\text { Uniones del mismo } \\
\text { sexo }\end{array}$ & $\begin{array}{l}\text { Matrimonio personas } \\
\text { del mismo sexo }\end{array}$ & $\begin{array}{l}\text { Adopción por parejas } \\
\text { del mismo sexo }\end{array}$ & $\begin{array}{l}\text { Servicio abierto } \\
\text { en las fuerzas } \\
\text { armadas }\end{array}$ & $\begin{array}{l}\text { Leyes de discriminación } \\
\text { de Orientación } \\
\text { sexual y/o identidad de } \\
\text { género }\end{array}$ & $\begin{array}{c}\text { Reconocimiento de } \\
\text { la identidad de género en } \\
\text { documentos }\end{array}$ \\
\hline $\begin{array}{c}\text { Legal } \\
\text { (desde 1871) }\end{array}$ & $\begin{array}{c}\text { Legal en } \\
\text { CDMX (2007) } \\
\text { Coa (2007) } \\
\text { Camp (2013) } \\
\text { Mich (2015) } \\
\text { Tlax (2017) }\end{array}$ & $\begin{array}{c}\text { Legal en } \\
\text { CDMX (2010) } \\
\text { Coa (2014) } \\
\text { Chih (2015) } \\
\text { Guerr (2015) } \\
\text { Nay (2015) } \\
\text { Jal (2016) } \\
\text { Camp (2016) } \\
\text { Mich (2016) } \\
\text { Mor (2016) } \\
\text { Col (2016) } \\
\text { Chia (2017) } \\
\text { Pue (2017) } \\
\text { BajCalif (2017) NueLe ( } \\
\text { 2019) } \\
\text { Agsc (2019) } \\
\text { Hid (2019) } \\
\text { SLP (2019) } \\
\text { BajCalSur (2019) }\end{array}$ & $\begin{array}{l}\text { Personas solteras } \\
\text { pueden adoptar. } \\
\text { Adopción conjunta en } \\
\text { CDMX (2010) } \\
\text { Coa (2014) } \\
\text { Cam (2015) } \\
\text { Col (2016) } \\
\text { Mich (2016) } \\
\text { Mor (2016) } \\
\text { Ver (2016) } \\
\text { Chia (2017) } \\
\text { Pue (2017) } \\
\text { BajCali (2017) }\end{array}$ & $\begin{array}{c}\text { Legal } \\
\text { (desde 2016) }\end{array}$ & $\begin{array}{c}\text { Prohibición } \\
\text { constitucional } \\
\text { contra toda forma de } \\
\text { discriminación basada } \\
\text { en las preferencias } \\
\text { sexuales. (desde 2011) } \\
\text { incluyendo el discurso } \\
\text { de odio. (desde 2014) }\end{array}$ & $\begin{array}{l}\text { Cambio de nombre y sexo } \\
\text { registral ilegal en } 23 \\
\text { estados, se requiere } \\
\text { permiso judicial. } \\
\\
\text { Legal en } 9 \text { estados sin } \\
\text { necesidad de permiso } \\
\text { judicial ni cirugías previas, } \\
\text { en CDMX (2014) } \\
\text { Mich (2017) Nay (2017) } \\
\text { Coa (2018) Hid (2019) } \\
\text { SLP (2019) Col (2019) } \\
\text { Oax (2019) Tlax (2019) }\end{array}$ \\
\hline
\end{tabular}

Fuente:https://es.wikipedia.org/wiki/Legislaci\%C3\%B3n_sobre_derechos_LGBT_en_el_mundo 
Con relación a las leyes de identidad de género todavía existe una amplia brecha política entre los estados (ver tabla 5). Toda política contribuye así a la reproducción o transformación de un orden social y político, la regulación de tensiones, la integración de grupos sociales y la resolución de conflictos. Una política es conducida con el fin de resolver en términos prácticos y simbólicos una situación considerada como socialmente problemática. Desde esta óptica las políticas públicas pueden ser vistas como un conjunto de posiciones políticas sucesivas del Estado sobre controversias o cuestiones sociales. La ausencia de políticas, es decir, el no actuar, también es una manera de tomar partido (Pecheny y De la Dehesa, 2011).

En un momento en que el sentido de la democracia se encuentra puesto en cuestión, de cara a la hegemonía neoliberal, Sabsay (2018) interroga la política de la ciudadanía sexual, focalizando su atención en la dimensión corporal de las luchas por la libertad y la justicia genérico-sexuales. Mientras que las fronteras, la racialización de los cuerpos y la regulación sexual han adquirido nuevos sentidos a la luz de este adverso momento político, se requiere un análisis sobre la manera en que los cuerpos devienen objetivo de nuevas batallas, y al mismo tiempo un arma de resistencia.

\section{Reflexiones problemáticas}

Para la Suprema Corte de Justicia de la Nación de México (SCJN, 2018), el Sistema Binario del Sexo y el Género (SBSG) es entendido como el modelo social y cultural dominante occidental que considera que el género y el sexo abarcan únicamente dos categorías rígidas, a saber, masculino/hombre y femenino/mujer. Es decir, se refiere a un conjunto de creencias de tipo conservador y claramente patriarcal que sostiene que: i) los sexos son dos y sólo dos: varón y mujer; ii) las relaciones sexuales tienen como fin la procreación y sólo la procreación y iii) la familia "natural" es patriarcal, monogámica, heterosexual y para toda la vida (Femenías, 2015).

Esta división binaria del sexo y del género ha sido aceptada como una verdad irrefutable y casi dogmática. Tal sistema o modelo excluye a aquellos individuos que no se enmarcan en las dos categorías. Dentro de las personas excluidas por este modelo se encuentran, entre otras de la diversidad sexual, las personas no binarias, transexuales, transgénero e intersexuales, pues para el Estado no entran dentro de la categoría de "hombre" o "mujer" en su sentido "biológicamente típico" y son casi siempre sometidos a procedimientos quirúrgicos y endocrinológicos muchas veces violando sus derechos (SCJN, 2018).

Dicho SBSG sigue siendo considerado por las sociedades actuales como único modelo posible de organización social. El cual, cuando es considerado como oposición dicotómica excluyente, coloca obstáculos que impiden vivir la corporeidad y la experiencia vital con autonomía (García-Granero, 2017). Es aquí donde la sexualidad se cruza con el estatus de ciudadanía en las democracias modernas; a partir de la segunda mitad del siglo XX, ésta ha adquirido un papel fundamental en todos los niveles estructurales de las sociedades capitalistas desarrolladas (Jiménez, 2018). Específicamente, la categoría de ciudadanía sexual existe debido a la primacía que tiene la subjetividad sexual en el mundo contemporáneo y constituye una nueva forma de pertenencia (Weeks,1998).

Algunas consecuencias del sistema esencialista binario del sexo/género a partir del cual se construye la identidad jurídica y la ciudadanía las ha documentado La Asociación Mundial para la Salud Sexual y la Organización Panamericana de la Salud (WAS y OPS, 2009) como violencia cultural y estructural hacia la diversidad sexual y de género, tales como: Patologización, criminalización e invisibilización del comportamiento sexual no normativo; Desvinculación de los programas de educación sexual con los comportamientos sexuales no normativos. Educación sexual heteronormativa, cisnormativa, binaria, coito-céntrica, monógama; Criminalización de estilos familiares como la 
poligamia donde los adultos en uniones polígamas consensuales (y sus hijos) carecen de acceso a sus derechos; Criminalización y control segregado del trabajo sexual; Utilización por parte del Estado y sus agentes de abuso verbal, acoso, violencia, la violación de la integridad física y el asesinato o la pena capital para castigar a hombres, mujeres, niños y niñas que infringen las normas culturales de conducta sexual. Por ejemplo, la pena de muerte puede ser impuesta y se impone por una convicción de homosexualidad en los países que se rigen por la ley islámica; la revictimización por parte de los profesionales de salud que trabajan en unidades de medicina forense, quienes violan la integridad física de las personas detenidas por sospecha de actividad homosexual, al efectuar exámenes anales forzados y repetidos con la finalidad de determinar su culpa; la colusión entre los profesionales de salud y la policía, en la vigilancia policial rigurosa y ruda con procesos penales o tratamiento médico forzado para las personas descubiertas en actividades homosexuales; la utilización de procedimientos quirúrgicos y tratamientos hormonales no supervisados por especialistas del Estado para las personas intersexuales y transexuales.

Para la ONU (2016) la discriminación de lesbianas, gays, bisexuales, travestis, transgénero, transexuales e intersexuales (LGBTTTI) no sólo perjudica a las personas, también reduce las ganancias de las empresas y cuesta a los países miles de millones de dólares en pérdidas, al reducir su rendimiento económico. Cada vez que una persona de la comunidad LGBTTTI es acosada o expulsada de su empleo, no sólo se comete una injusticia contra un ser humano, sino que también se pierde una oportunidad para consolidar una economía más productiva.

Por ejemplo, en un estudio piloto que llevó a cabo el Banco Mundial (Badgett, 2014) concluyó que la discriminación de las personas del colectivo LGBT en la India podría costar actualmente a ese país hasta 32.000 millones de dólares estadounidenses al año por la pérdida de rendimientos económicos que representa. Por lo que el Secretario General de las Naciones Unidas, Ban Ki-moon, afirmó que la erradicación de la discriminación contra los miembros del colectivo LGBTTTI es "una prioridad en materia de derechos humanos y una exigencia del desarrollo" (ONU, 2016 p.1).

Particularmente en México, el inicio del nuevo milenio se encuentra enmarcado por lo que se conoce como "periodo de transición democrática", en donde los cambios en el sistema político no solo se viven con la aparición de nuevos actores, sino también con el nacimiento de nuevas instituciones como el Consejo Nacional para Prevenir la Discriminación (CONAPRED) y la instauración de un valor central: el respeto a la diferencia (López, 2018).

El CONAPRED (2019) señala que las personas LGBTTTI enfrentan obstáculos sustantivos en el ejercicio de todo tipo de derechos. En el acceso a la educación, al empleo o a la salud, e incluso en el mismo proceso de desarrollo de la identidad, las personas que tienen una orientación sexual, identidad o expresión de género, o características sexuales diversas encuentran barreras motivadas por prejuicios sociales u omisiones legales. Generalmente, dichos prejuicios provienen de la valoración positiva que se da a la heterosexualidad, así como a la presunta congruencia que se cree debería existir entre la identidad de género de una persona y el sexo que le fue asignado al nacer, o bien a las características corporales que se consideran "normales" (binarismo sexo-género). En ocasiones, esto contribuye a casos de violencia que pueden terminar con la vida de las personas. La discriminación por orientación sexual, identidad y expresión de género, y características sexuales diversas tiene una naturaleza estructural. Es un proceso con raíces históricas que se alimenta de los estereotipos asociados con la diversidad sexual. Dichos estigmas han justificado una diferencia de trato, y se encuentran tan arraigados en nuestra cultura que inciden no sólo en el ámbito privado principalmente en la familia - sino también en el público - por ejemplo, en las instituciones de seguridad social o de acceso a la justicia.

EI CONAPRED (2019) detalla que de acuerdo con la Encuesta Nacional sobre Discriminación (Enadis) 2017, casi 2 millones 700 mil personas en México declaran no ser heterosexuales, lo cual representa 
3.2\% de la población nacional. No obstante, es probable que, dados los prejuicios sobre la diversidad sexual, algunas de las personas no hayan compartido su orientación sexual abiertamente y el porcentaje sea mayor.

Al mismo tiempo, de acuerdo con un estudio difundido por UCLA, $0.6 \%$ de la población estadounidense se identifica como trans. En cifras absolutas, la cifra asciende a 1.4 millones de personas (Flores, et. al 2016). Si la proporción fuera idéntica en México, estaríamos hablando de aproximadamente 740 mil personas.

Por otra parte, la estimación más recurrente en torno al número de personas intersex en el mundo es de una en 1,500; sin embargo, la Organización Internacional Intersex plantea que el cálculo más apropiado es $1.7 \%$ de la población. Dicho valor parte de los estudios de Anne Fausto-Sterling, una reconocida experta en la materia (Organisation Intersex International, 2013).

Igualmente, la estigmatización de la diversidad ha conducido a que, en muchos ámbitos, se reproduzcan patrones de discriminación. En un diagnóstico, siete de cada diez personas LGBTI declararon haberse sentido discriminadas en espacios educativos y la mitad manifestó haber vivido, por lo menos una vez, situaciones de acoso, hostigamiento o discriminación en el trabajo (CEAV y Fundación Arcoiris 2016). En otro estudio, 42\% de las mujeres trans, $38 \%$ de los hombres trans y $39 \%$ de las mujeres lesbianas expresaron haber sido discriminadas y discriminados en el espacio público (Mendoza et al. 2015).

Por su parte, la Comisión Interamericana de Derechos Humanos en su documento Violencia contra personas LGBTI y el Comunicado de Prensa 137/15, indica que el $80 \%$ de las personas trans asesinadas durante un período de 15 meses tenía 35 años de edad o menos, en comparación con el porcentaje de personas asesinadas con menos de 35 años, que acorde a los datos del INEGI corresponde al 50\% y 54\% de hombres y mujeres asesinadas en 2015 en México.

En consecuencia, el CONAPRED (2019) describe que, entre los temas prioritarios, se encuentran: la inclusión de la orientación sexual, la expresión e identidad de género, y las características sexuales dentro de los motivos prohibidos de discriminación, en lugar de las "preferencias sexuales" (como aparece actualmente en el artículo $1^{\circ}$ de la Constitución). Combatir e investigar de manera adecuada los crímenes de odio hacia las personas LGBTTTI, así como adoptar medidas contra el acoso escolar homofóbico, lesbofóbico, bifóbico, transfóbico e interfóbico. Con respecto a esto último, se debe prestar especial atención a la prevención del suicidio y otras afecciones psicoemocionales entre las infancias LGBTTTI. La reforma a la Ley de Seguridad Social y a la Ley del ISSSTE para que la afiliación de cónyuges entre parejas del mismo sexo sea un derecho más accesible. Así mismo, las actas de nacimiento que reconozcan la identidad de género de las personas deben poder obtenerse mediante un procedimiento administrativo en todo el territorio mexicano. Visibilizar la existencia de las personas intersexuales y erradicar las cirugías que les asignan un sexo a muy corta edad. Garantizar especialmente en cuestiones como salud, el acceso de las personas LGBTTTI a servicios especializados y específicos a sus necesidades, sin discriminación alguna. Finalmente, aún hace falta que el acceso al matrimonio no esté condicionado a que se ostente una orientación sexual específica (la heterosexual), como aún sucede en la mayoría del territorio nacional.

La negación de derechos se agudiza y alcanza sus niveles de discriminación y violencia más altos con las personas transgénero, pues no entran en el modelo de normal, aceptable y deseable; es decir, son personas que carecen de alineación entre su sexo, género, práctica y deseo; y cuya lucha por una ciudadanía libre de discriminación y violencia no ha terminado aún (López y Serrato, 2018).

En este sentido, la Clasificación Internacional de Enfermedades (CIE) de la Organización Mundial de la Salud (OMS) fue revisada a mediados del 2019 por un grupo de trabajo de expertos quienes 
tuvieron por objetivos centrales: 1) la despatologización y desestigmatización de las personas denominadas "transgénero»; y 2) posibilitar el tratamiento y servicios de salud accesibles y de calidad para las personas que así lo requieran (Robles y Ayuso-Mateo, 2019:66).

Sin embargo, a pesar de los recientes esfuerzos de la OMS por despatologizar y desestigmatizar dichas condiciones, en México continúa siendo un desafío garantizar el derecho a la autodeterminación de la identidad de género y las demandas en torno al ejercicio de los derechos humanos de las personas transgénero (López, 2018).

La violencia extrema a este colectivo está reflejada en el informe del Observatorio de Personas Trans Asesinadas (OPTA, 2016), el cual reportó que México ocupa el segundo lugar mundial con 285 casos de personas transgénero asesinadas de enero de 2008 a junio de 2016, después de Brasil con 868 asesinatos en el mismo periodo.

Desafortunadamente, prevalece la creencia científica de que, al paso de los años, la noción de ciudadanía se perfecciona y se vuelve más incluyente; no obstante, en el modelo normativo de democracia predominan las ciudadanías uniformes y heteronormadas, con lo que no se da cabida a lo diverso. Este paradigma, entonces, desconoce, entre otras ciudadanías, a las sexuadas, con lo que se les niega el pleno ejercicio de sus derechos. Las personas de la diversidad sexual no sólo están en la lucha del goce de derechos y obligaciones como los ciudadanos que son reconocidos por el modelo normativo, sino también dando la batalla en la reconfiguración sociocultural (López y Serrato, 2018).

\section{Conclusiones}

El contexto de expansión de la ciudadanía sexual - esto es, la reinterpretación de las sexualidades a través del lenguaje de la ciudadanía y los derechos - varía ampliamente según contextos y genealogías particulares. Desde el punto de vista de la igualdad de derechos y los ideales antidiscriminatorios, todas las luchas por los derechos LGBTTTI son indiscutiblemente legítimas. Tienen que ver con el acceso de las personas cuya sexualidad o género no se corresponden con los parámetros heteronormativos, a los derechos concebidos como universales. Se trata de su inclusión dentro de la ciudadanía, donde la ciudadanización de muchxs disidentes u "otrxs" sexuales implica un tratamiento en pie de igualdad. Este reconocimiento es en parte deudor de lo que se ha entendido como la judicialización de los reclamos LGBTTTI, es decir, la concentración de recursos en la modificación de los marcos legales existentes principalmente en función del derecho a la identidad y el respeto a la diferencia (Sabsay, 2018).

Para el Gobierno de México (SEGOB, 2020) la identidad de género es "el concepto que se tiene de uno mismo como ser sexual y de los sentimientos que esto conlleva; se relaciona con cómo vivimos y sentimos nuestro cuerpo desde la experiencia personal y cómo lo llevamos al ámbito público, es decir, con el resto de las personas. Se trata de la forma individual e interna de vivir el género, la cual podría o no corresponder con el sexo con el que nacimos".

Esta afirmación relaciona de una manera biologicista la identidad de género con la asignación del sexo al nacer derivado de la interpretación anatómica de los órganos sexuales pélvicos externos (pene y vulva) bajo el sistema normativo binario. Por lo que añade "si bien existe una diversidad de identidades de género, habitualmente se considera un espectro con dos extremos: la identidad atribuida a las mujeres y la relacionada con los hombres. Sin embargo, debemos recordar que la identidad de género:

- Es independiente de la orientación sexual e incluye las formas en las que una persona se autodenomina y presenta frente a las demás. 
- Incluye la libertad de modificar la apariencia o la función corporal a través de roles sociales de género, técnicas médicas, quirúrgicas o de otra índole".

Por lo anterior, se considera que el sistema binario sexo-género a partir del cual el Estado mexicano se organiza y garantiza el derecho a la identidad de género en el artículo 40 de la Constitución Política de los Estados Unidos Mexicanos (DOF, 2019) representa un obstáculo para la construcción de ciudadanía sexual plena y de posibilidades de libre expresión de individuos que por sus características bio-psico-culturales no se ajustan a la norma política y social binaria del sexo y del género. Por lo tanto, sostiene la violencia simbólica que se vive en la cotidianidad de los cuerpos, las identidades y las expresiones de género abyectas y marginales. El sistema binario del sexo y del género está siendo superado por la realidad de, los cada vez más, colectivos de las diversidades sexuales y de género.

Las controversias más recientes en México tienen que ver con el reconocimiento de la identidad de género en menores de edad que viven discordancia de género. A lo que la actual secretaria de gobernación Sánchez Cordero advirtió que "el Legislativo tiene otros retos para combatir la discriminación por orientación sexual e identidad o expresión de género, como promover el reconocimiento de la identidad de género de todas las personas, incluidas niñas, niños y adolescentes" (Agencia Reforma, 2020).

En este sentido, el 30 de octubre de 2020, Enrique Alfaro, Gobernador del Estado de Jalisco aprobó las reformas al Reglamento del Registro Civil del Estado por lo que, con ese decreto, las personas podrán acudir a cualquier oficialía de registro civil para hacer valer su derecho a la identidad y obtener un acta de nacimiento acorde a su identidad. El mandatario estatal compartió en redes sociales el decreto y destacó que "las personas trans podrán hacer valer su derecho y obtener un acta de nacimiento acorde a su identidad" incluidas las infancias y las juventudes trans (Milenio, 2020).

Sin embargo, los desafíos siguen siendo muchos, desde el activismo y la academia habrá que continuar argumentando y visibilizando la des-naturalización y la des-esencialización de las identidades de género de manera que la diversidad y la fluidez de las identidades y expresiones de género pueda tener la oportunidad de inclusión en la construcción dialógica de la ciudadanía de la mano con otras luchas decoloniales, anti-capitalistas y anti-patriarcales. 


\section{Bibliografía}

Acosta, M., Costales, Z., Meisozo, N., y Borges, A. (2015). Sexualidad y discapacidad: enfrentando estereotipos desde el documental audiovisual. Revista Cubana de Información en Ciencias de la Salud, 26(3), 273-279.

Adrián, T. (2008). Bases conceptuales de una normativa que asegure la igualdad de los derechos a las lesbianas, homosexuales, transexuales y transgéneros en Venezuela, en Cuerpos y diversidad sexual: aportes para la igualdad y el reconocimiento. Ed., Pontificia Universidad Javeriana.

Agencia Reforma. (2020). La Secretaría de Gobernación pide eliminar terapias que "curan" la homosexualidad. En red: https://sipse.com/mexico/secretaria-de-gobernacion-pide-eliminarterapias-que-curan-la-homosexualidad-365565.html

Aguilar, T. (2008). El sistema sexo-género en los movimientos feministas. AMNIS. Revue de civilisation contemporaine Europes/Amériques. (8).

Álvarez-Gayou, J. L. (2002). Homosexualidad: derrumbes de mitos y falacias. México: Benemérita Universidad de Puebla.

Amuchástegui A. y Rivas M. (2004). Los procesos de apropiación subjetiva de los derechos sexuales: notas para la discusión. Estudios demográficos y urbanos, 543-597.

Amuchástegui A. y Rivas M. (2008). Construcción subjetiva de ciudadanía sexual en México: Género, heteronormatividad y ética. En: Salas, G. (2008). Sexualidad, derechos humanos y ciudadanía: diálogos sobre un proyecto en construcción. El Colegio de México AC.

Antonio, J. (2017). Los derechos LGBT en México: Acción colectiva a nivel subnacional. European Review of Latin American and Caribbean Studies/Revista Europea de Estudios Latinoamericanos y del Caribe, (104), 69-88.

Arguello, S. (2012). El proceso de politización de la sexualidad: identificaciones y marcos de sentido de la acción colectiva. Revista mexicana de sociología, 75(2), 173-200.

Badgett, M. V. (2014). The economic cost of stigma and the exclusion of LGBT people: a case study of India. Washington, D.C.: World Bank Group

Balza, I. (2009). Ciudadanía y nuevas identidades de género: sobre biopolítica y teoría queer. Presente, pasado y futuro de la democracia, 231-238.

Balzer, C. (2011). "Eu acho transexual e aquele que disse: eu sou transexual" reflexiones etnológicas sobre la medicalización globalizada de las identidades trans a través del ejemplo de brasil. In M. Missé \& G. Coll - Planas (Eds.), El género desordenado. Críticas en torno a la patologización de la transexualidad (pp. 81-96). Barcelona: Egales.

Banco Mundial (2017). Orientación sexual e identidad de género. Reseña. Recuperado el 15 de noviembre de 2019.2 En red: https://www.bancomundial.org/es/topic/socialdevelopment/brief/sexual-orientation-and-genderidentity

Bao, A. M. y Swaab, D. F. (2011). Sexual differentiation of the human brain: relation to gender identity, sexual orientation and neuropsychiatric disorders. Frontiers in Neuroendocrinology, 32, 214-226.

Barañano, A., García, J., Cátedra, M. y Devillard, M. (2007). Diccionario de relaciones interculturales. Diversidad y globalización. Editorial Complutense.

Bauman, Z. (2003). De peregrino a turista, o una breve historia de la identidad, en Hall, S. y Du Gray, P. (Comp.). Cuestiones de identidad cultural. Buenos Aires: Amorrortu

Revista del Laboratorio Iberoamericano para el Estudio Sociohistórico de las Sexualidades https://doi.org/10.46661/relies.5212 
Bell, D. y Binnie, J. (2000) The Sexual Citizen: Queer Politics and Beyond. Cambridge: Polity Press.

Benedicto, B. (2014). Under Bright Lights: Gay Manila and the Global Scene. Minneapolis, MI: University of Minnesota Press.

Betevé (2018, junio 7). Entrevista a Paul B. Preciado [Archivo de video]. Recuperado de: https://www.youtube.com/watch?v=04Uibmsg0zc

Bianco, F. et al. (2013). Sexo, género y ciudadanía. Comunidad y Salud, 11(1),1-7.

Bockting, W. O., Miner, M. H., Swinburne, R. E., Hamilton, A., y Coleman, E. (2013). Stigma, mental health, and resilience in an online sample of the US transgender population. American journal of public health, 103(5), 943-951.

Boellstorff, T. (2005). The Gay Archipelago: Sexuality and Nation in Indonesia. Princeton, NJ: Princeton University Press.

Boellstorff, T. (2007). A Coincidence of Desires: Anthropology, Queer Studies, Indonesia. Durham, NC: Duke University Press.

Bouman, W. P., Claes, L., Brewin, N., Crawford, J. R., Millet, N., Fernandez-Aranda, F., y Arcelus, J. (2017). Transgender and anxiety: A comparative study between transgender people and the general population. International Journal of Transgenderism, 18(1), 16-26.

Boza, C., y Nicholson, K. (2014). Gender-related victimization, perceived social support, and predictors of depression among transgender Australians. International Journal of Transgenderism, 15(1), 35-52.

Bradford, J., Reisner, S. L., Honnold, J. A., y Xavier, J. (2013). Experiences of transgender-related discrimination and implications for health: results from the Virginia Transgender Health Initiative Study. American journal of public health, 103(10), 1820-1829.

Butler, J. (2002). Críticamente subversiva. En R. M. Mérida-Jiménez, Sexualidades transgresoras. Una antología de estudios queer. Barcelona: Icaria.

Butler, J. (2007). El género en disputa. El feminismo y la subversión de la identidad. España: Paidós Ibérica.

Cabral, M. (2003). Ciudadanía (trans) sexual. Proyecto sexualidades, salud y derechos humanos en América Latina. En

red: http://polux.cmq.edu.mx/liblaicas/images/articulos/10/01/02/100102013.pdf

Cáceres, C. F., Frasca, T., Pecheny, M., y Terto Júnior, V. (2004). Ciudadanía sexual en América Latina: abriendo el debate. Lima. Perú; Universidad Peruana Cayetano Heredia

Cardona-Cuervo, J. (2016). La construcción de los derechos del grupo social transgénero. Entramado, 12(2), 84-95.

Careaga, G., y Cruz, S. (2004). Sexualidades diversas: aproximaciones para su análisis. Miguel Angel Porrua. México.

Carrillo, B., et al. (2010). Cortical activation during mental rotation in male-tofemale and female-tomale transsexuals under hormonal treatment. Psychoneuroendocrinology, 35, 1213-1222.

Castilla-Peón, M. F. (2018). Manejo médico de personas transgénero en la niñez y la adolescencia. Boletín médico del Hospital Infantil de México, 75(1), 7-14.

Cauldwell, D. O. (2001). Psichopatia transexualis. The International Journal of Trangederism, 5(2). Originally published in Sexology, vol. 16, 1949, pp. 274-280. Copyright, 1949, by Sexology Magazine.

Revista del Laboratorio Iberoamericano para el Estudio Sociohistórico de las Sexualidades https://doi.org/10.46661/relies.5212 
Chomsky, N., y Herman, E. (1990): Los guardianes de la libertad. Traducción de Carme Castells. Grijalbo Mondadori, Barcelona.

Choza, J., y Piulats, O. (1999). Identidad Humana y fin del milenio. Thémata, 387-392.

Coleman E., et al. (2012) Standards of Care for the Health of Transsexual, Transgender, and GenderNonconforming People, Version 7, International Journal of Transgenderism, 13:4, 165-2

Coll-Planas, G. (2010). La voluntad y el deseo. Madrid: Egales.

CONAPRED (2019). Ficha temática: Orientación sexual, características sexuales e identidad y expresión de género. Recuperado en red el 18 de septiembre de 2019 . En: https://www.conapred.org.mx/userfiles/files/FichaTematica_LGBTI.pdf

Cresswell, J. (1998). Qualitative Inquiry and Research Design. Choosing Among Five Traditions. Londres: Sage Publications.

Crozier, I. (2008). Pillow talk: credibility, trust and the sexological case history. History of Science, 46(4), 375-404.

Dahl, M., Feldman, J. L., Goldberg, J. M., y Jaberi, A. (2006). Physical aspects of transgender endocrine therapy. International Journal of Transgenderism, 9(3-4), 111-134.

De Beauvoir, S. (1981). El segundo sexo (1949). Buenos Aires: Siglo XX.

De la Hermosa-Lorenci, M. (2013). Repensando los orígenes de la disforia de género. Revista de Estudios de Juventud, №. 103, 2013 (Ejemplar dedicado a: Juventud, neurociencia, tecnología y subjetividad), págs. 33-50

De Lauretis, T. (1987). Technologies of Gender: Essays on Theory, Film, and Fiction. Bloomington: Indiana University Press.

De Santis, J. (2009). HIV infection risk factors among male-to-female transgender persons: A review of the literature. Journal of the Association of Nurses in AIDS Care, 20(5), 362-372.

De Vicente, A., Berdullas, S. y Castilla, C. (2012). Se cuestiona el modelo biologicista en salud mental. Infocop, 57, 3-7

Dellacasa, M. A. (2014). Violencia de estado: el reconocimiento de las personas transexuales como sujetos "patológicos" de derechos. Maguaré, 28(1).

Den Heijer, M., Bakker, A., y Gooren, L. (2017). Long term hormonal treatment for transgender people. Bmj, 359.

Descartes, R. (2005). Meditaciones metafísicas, España: Alianza editorial.

Dèttore, D., et al. (2015). Gender dysphoria in adolescents: the need for a shared assessment protocol and proposal of the AGIR protocol. J Psychopathol, 21, 152-158.

Di Marco, G. (2012). Las demandas en torno a la Ciudadanía Sexual en Argentina. SER Social, 14(30), 210-243.

Díaz, L., Torruco, U., Martínez, M., \& Varela, M. (2013). La entrevista, recurso flexible y dinámico. Investigación en educación médica, 2(7), 162-167.

DOF (2019). Diario Oficial de la Federación. Constitución Política de los Estados Unidos Mexicanos. Cámara de Diputados $H$. Congreso de la Unión. Disponible en: http://www.diputados.gob.mx/LeyesBiblio/pdf/1_090819.pdf

Domínguez, C. M., Ramírez, S. V., y Arrivillaga, M. (2018). Acceso a servicios de salud en mujeres transgénero de la ciudad de Cali, Colombia. MedUNAB, 20(3), 296-309.

Revista del Laboratorio Iberoamericano para el Estudio Sociohistórico de las Sexualidades https://doi.org/10.46661/relies.5212 
Domínguez, J., García, P. y Hombrados, M. (2012). Transexualidad en España. Análisis de la realidad social y factores psicosociales asociados. En red: https://www.west-info.eu/transsexual-censusIgbt-homosexuality/transexualidad/

Ehrensaft, D., Giammattei, S. V., Storck, K., Tishelman, A. C., y Keo-Meier, C. (2018). Prepubertal social gender transitions: What we know; what we can learn-A view from a gender affirmative lens. International Journal of Transgenderism, 19(2), 251-268.

Embree, L. (2009). Intra-culturalidad: género, generación y relaciones de clase en Schutz. Acta fenomenológica latinoamericana, 3, 179-193.

Enríquez, G. A., y Martínez, C. (2016). Ciudadanía y cuerpos: reconfigurando la ciudadanía desde la diversidad. Sinéctica, Revista Electrónica de Educación, (46),1-13.

Erickson, E. (1977). La identidad psicosocial. Enciclopedia Internacional de las Ciencias Sociales, tomo V, España: Aguilar.

Evans, D. (1993). Sexual Citizenship: The Material Construction of Sexualities. London: Routledge.

Evans, D. (2007). Sexual citizenship. The Blackwell Encyclopedia of Sociology.

Fausto-Sterling, A. (2006). Cuerpos Sexuados. La política del género y la construcción de la sexualidad. Ed. Melusina. Barcelona, España.

Femenías, M. L. (2015). Del sexo binario a la diversidad de géneros: algunas contribuciones teóricas. Publicado en: Assis, Z. y M. Guadalupe Dos Santos (comp.) Diferencia sexual $e$ deconstruÇão de subjetividade em perspectiva, Belo Horizonte, DPlacido, 165-186.

Fernández, M., y García-Vega, E. (2012). Surgimiento, evolución y dificultades del diagnóstico de transexualismo. Revista de la asociación española de neuropsiquiatría, 32(113), 103-119.

Fernández, R. M. y Pásaro, E. (2017). ¿La identidad sexual es una opción? Un estudio sobre la base genética de la Transexualidad. Cuadernos de Bioética, 28, 343- 353.

Fine, C. (2011). Cuestión de sexos. Barcelona: Roca editorial.

Fish, J. (2007). Getting equal: the implications of new regulations to prohibit sexual orientation discrimination for health and social care. Diversity in Health and Social Care, 4(3), 221-228.

Flichtentrei, D. (2018). Posverdad: la ciencia y sus demonios. Inmanencia. Revista del Hospital Interzonal General de Agudos (HIGA) Eva Perón, 6(1) 114-118.

Fraser, N. (2008). La justicia social en la era de la política de identidad: redistribución, reconocimiento y participación. Revista de trabajo, 4(6) 83-99.

García-Falgueras, A. et al. (2005). The role of the androgen receptor in CNS masculinization. Brain Research, 1035, 13-23.

García-Granero, M. (2017). Deshacer el sexo. Más allá del binarismo varón-mujer. Dilemata, (25), 253-263.

García-Ruíz, M. y De Dios, R. (2000). Transexualidad: una revisión del estado actual del tema. Anuario de Sexología, 6, 127-141

Gastó, C. (2006). Transexualidad. Aspectos históricos y conceptuales. Cuadernos de Medicina Psicosomática y psiquiatría de Enlace, 78, 13-20.

Giddens, A. (1992). La transformación de la intimidad Sexualidad, amor y erotismo en las sociedades modernas. Ed. Cátedra. España. 
González, A. (2013). Los conceptos de patriarcado y androcentrismo en el estudio sociológico y antropológico de las sociedades de mayoría musulmana. Papers. Revista De Sociologia, 98(3), 489504. doi:http://dx.doi.org/10.5565/rev/papers/v98n3.335

González, R. (2002). Sujeto y Subjetividad: una aproximación histórico-cultural. C. de México: Thomson.

Gooren, L., Bowers, M., Lips, P., y Konings, I. R. (2015). Five new cases of breast cancer in transsexual persons. Andrologia, 47(10), 1202-1205.

Grabham, E. (2007). Citizen bodies, intersex citizenship. Sexualities 10(1): 29-48.

Granero, M. (2014). Sexología basada en la evidencia: historia y actualización. Revista Costarricense de Psicología, 33(2), Disponible en: https://www.redalyc.org/articulo.oa?id=4767/476747238002

Gros, A. E. (2016). Judith Butler and Beatriz Preciado: a comparison of two theoretical models of the construction of gender identity in Queer theory. Civilizar Ciencias Sociales y Humanas, 16(30), 245260.

Grossman, A. y D'Augelli, A. (2007). Transgender youth and life-threatening behaviors. Suicide and Life-Threatening Behavior, 37(5), 527-537.

Hall, S. (2003). ¿Quién necesita identidad? en Hall, S. y Du Gray, P. (Comp.). Cuestiones de identidad cultural. Buenos Aires: Amorrortu

Haraway, D. (1995). Ciencia, cyborgs y mujeres: la reinvención de la naturaleza. Ed. Cátedra. Universitat de València. España.

Hernández, P. (2004). Los estudios sobre diversidad sexual en el PUEG. En Careaga, G., \& Cruz, S. (Comp.) (2004). Sexualidades diversas: aproximaciones para su análisis. (p 21-33). Miguel Angel Porrua. México.

Heylens, G., et al. (2014). Psychiatric characteristics in transsexual individuals: multicentre study in four European countries. The British Journal of Psychiatry, 204(2), 151-156.

Hines, S. (2009). A pathway to diversity? Human rights, citizenship and politics of transgender. Contemporary Politics 15(1): 87-102.

Jackson, P.A. (2011) Queer Bangkok: Twenty-First Century Media, Markets and Rights. Hong Kong: Hong Kong University Press.

Jiménez, J. (2018). Ciudadanía sexual en Costa Rica: los actos, las identidades y las relaciones en perspectiva histórica. Revista Interdisciplinaria de Estudios de Género de El Colegio de México, 4, http://dx.doi.org/10.24201/eg.v4i0.152

Johnson, C. (2017). Sexual citizenship in a comparative perspective: Dilemmas and insights. Sexualities, 20(1-2), 159-175.

Junger, J., et al. (2014). More than just two sexes: the neural correlates of voice gender perception in gender dysphoria. PLoS One.

Kennedy, H. C. (1981). The "Third Sex" Theory of Karl Heinrich Ulrichs. Journal of Homosexuality, 6(1-2), 103-111. doi:10.1300/j082v06n01_10

Krafft-Ebing, R. (1998). Psychopathia sexualis: With especial reference to the antipathic sexual instinct: A medico-forensic study. New York, Arcade Publishing.

Laclau, E. (1994). Nuevas reflexiones sobre la revolución de nuestro tiempo, Buenos Aires: Nueva Visión. 
Laclau, E. y Mouffe, Ch. (2004). Hegemonía y estrategia socialista, hacia una radicalización de la democracia, Ciudad de México: Fondo de Cultura Económica.

Lamm, E. (2018). Identidad de género. Sobre la incoherencia legal de exigir el sexo como categoría jurídica. Actualidad jurídica iberoamericana, (8), 230-278.

Langarita, A. J. y Mas, J. (2017). Antropología y diversidad sexual y de género en España. Hacia la construcción de una especialidad disciplinaria. Revista de Dialectología y Tradiciones Populares. 72. 311. 10.3989/rdtp.2017.02.001.

Lerner, G. (1990). La Creación del Patriarcado. Ed. Novagrafik, Critica/Historia.

List, M. (2004). La Diversidad sexual vista por la antropología. En: G. Careaga y S. Cruz, Coord. Sexualidades Diversas, aproximaciones para su análisis. Ed. Miguel Angel Porrua. México.

López, E. y Serrato, A. (2018). Entre la patologización y el ejercicio de la ciudadanía plena: La experiencia de las personas LGBTTTI. Culturales, 6.

López, M. F. (2018) Patologización y despatologización de las identidades trans y su expresión en la ciudad de México. Un estudio monográfico. Biblioteca Jurídica Virtual del Instituto de Investigaciones Jurídicas de la UNAM.

López-Guzmán, J. (2018). El «mejor interés» del menor transexual. Bioethics Update.

Mackie, V. (2016). Rethinking sexual citizenship: Asia-Pacific perspectives. Sexualities, 20(1-2), 143158.

Mackie, V. y McLelland, M. (2015). Introduction: Framing sexuality studies in East Asia. En: McLelland, M. and Mackie, V. (eds.) Routledge Handbook of Sexuality Studies in East Asia. Abingdon: Routledge, pp. 1-17.

Maffia, D. (2001). Ciudadanía Sexual. Feminaria, XIV, 26-27, Recuperado de http://respublica.com.ar/Feminaria/Feminaria26-27.pdf

Maldonado, A. M., y Oliva, A. V. H. (2010). El proceso de construcción de la identidad colectiva. Convergencia. Revista de Ciencias Sociales, 17(53), 229-251.

Martínez, A. P. G. (2015). Identidades trans femeninas: sociabilidades, Internet, narrativas y tránsitos de género en la Ciudad de México (Doctoral dissertation).

Mèlich, J.C. (2010). Poética de lo íntimo (sobre ética y antropología). Ars Brevis: anuario de la Càtedra Ramon Llull Blanquerna, (16), 314-331.

Mendoza, A. L. R., y Soriano, A. F. (2009). Género y sexualidad en las universidades públicas mexicanas. Íconos, (35), 67-76.

Milenio. (2020). Jalisco dice sí a los derechos trans en todas sus edades. En red: https://www.milenio.com/politica/comunidad/jalisco-dice-si-a-los-derechos-trans-en-todas-susedades

Missé, M., y Coll-Planas, G. (2010). La patologización de la transexualidad: Reflexiones críticas y propuestas. Norte de salud mental, 8(38), 44-55.

Mitjáns-Martínez, A. (2008). Subjetividad, complejidad y educación. Psicología para América Latina, (13), 0-0.

Money, J. (1975). Ablatio penis: normal male infant sex-reassigned as a girl. Archives of Sexual Behaviour, 4, 65-71 
Money, J. (1994). The concept of gender identity disorder in childhood and adolescence after 39 years. Journal of Sex and Marital Therapy, 20,163-177.

Monro, S. (2005). Gender Politics: Activism, Citizenship and Sexual Diversity. London: Pluto Press. Monro, S. (2015). Bisexuality: Identities, Politics and Theories. Basingstoke: Palgrave Macmillan.

Moreno, D. C. (2014). Derecho, persona e identidad sexual. El debate jurídico de la documentación de las personas trans. Universitas Estudiantes, (11), 123-143

Navarrete-Cazales, Z. (2015). ¿Otra vez la identidad?: Un concepto necesario pero imposible. Revista mexicana de investigación educativa, 20(65), 461-479.

Nieto, J. A. (1993). Sexualidad y deseo: crítica antropológica de la cultura. Madrid: Siglo XXI.

OEA (2008). Orientación sexual e identidad de género, Resolución AG/RES.2435 (XXXVIII-O/08), aprobada por la Asamblea General de la Organización de los Estados Americanos durante su 38응 sesión, del 3 de junio de 2008, en Colombia, disponible en <http://bit.ly/1GLTF2h>, página consultada el 12 de marzo de 2019.

OEA (2012). Consejo Permanente de la Organización de los Estados Americanos, Orientación sexual, identidad de género y expresión de género: algunos términos y estándares relevantes, OEA/Ser.G CP/CAJP/INF. 166/12, 23 de abril de 2012, disponible en <http://bit.ly/1PPpBWa>, página consultada el 12 de marzo de 2019.

Olson, K. R., Durwood, L., DeMeules, M., y McLaughlin, K. A. (2016). Mental health of transgender children who are supported in their identities. Pediatrics, 137(3).

OMS (2004). Estrategia de salud reproductiva para acelerar el avance hacia la consecución de los objetivos y las metas internacionales de desarrollo. Recuperado el 12 de septiembre de 2019. En red:

https://apps.who.int/iris/bitstream/handle/10665/69040/WHO_RHR_04.8_spa.pdf?sequence=1

OMS (2006). Defining sexual health: Report of a technical consultation on sexual health, 28-31 January 2002. Geneva, World Health Organization.

OMS (2010). Developing sexual health programmes: a framework for action. Recuperado el 20 de septiembre de 2019.2 En red: http://www.who.int/reproductivehealth/publications/sexual_health/rhr_hrp_10_22/en/

OMS (2015). Sexual health, human rights and the law. Recuperado el 22 de septiembre de 2019. En red: http://www.who.int/reproductivehealth/publications/sexual_health/sexual-health-humanrights-law/en/

ONU (2008). Carta de fecha 18 de diciembre de 2008 dirigida al Presidente de la Asamblea General por los Representantes Permanentes de la Argentina, el Brasil, Croacia, Francia, el Gabón, el Japón, Noruega y los Países Bajos ante las Naciones Unidas, A/63/635, 22 de diciembre de 2008, disponible en <http://bit.ly/1zhVJre>, página consultada el 11 de marzo de 2019.

ONU (2016). Vidas destrozadas, pérdidas empresariales y crecimiento endeble: el verdadero costo de la discriminación. Recuperado en red el 18 de septiembre de 2019. En: https://www.ohchr.org/SP/NewsEvents/Pages/CostOfDiscrimination.aspx

OPTA (2016). Observatorio de Personas Trans Asesinadas. Recuperado en red el 2 de noviembre de 2019. En: https://transrespect.org/es/map/trans-murder-monitoring/

Ortega-Pavesio, A. (2019). Pacientes transgénero: ¿es necesario un programa de Educación para Enfermeras? Tesis de grado de la Facultad de Enfermería de Valladolid Universidad de Valladolid.

Revista del Laboratorio Iberoamericano para el Estudio Sociohistórico de las Sexualidades https://doi.org/10.46661/relies.5212 
España. En red: https://uvadoc.uva.es/bitstream/handle/10324/36780/TFGH1571.pdf?sequence=1\&isAllowed=y

Pachano, S. (2003). Ciudadanía e identidad. Facultad Latinoamericana de Ciencias Sociales, Sede Académica de Ecuador.

Parrini, R., y Amuchástegui, A. (2008). Un nombre propio, un lugar común. Subjetividad, ciudadanía y sexualidad en México: el Club Gay Amazonas. Debate feminista, 37, 179-196.

Pauley, I. B. (1969). Adult manifestations of female transsexualism. En R. Green \& J. Money (Eds.), Transsexualism and Sex Reassignment (pp. 34-58). Baltimore: John Hopkins Press.

PDIS (2018, Noviembre, 27). [Public Digital Innovation Space]. Conversation with Paul B. Preciado. [Archivo de video]. Recuperado de: https://www.youtube.com/watch?v=p1g01eFWei4

Pecheny, M., y De la Dehesa, R. (2011). Sexualidades y políticas en América Latina: un esbozo para la discusión. Sexualidade e política na América Latina: histórias, interseções e paradoxos, 31-79.

Plummer, K. (1995). Telling Sexual Stories: Power, Change and Social Worlds. London: Routledge.

Plummer, K. (2001), The Square of Intimate Citizenship: Some Preliminary Proposals. Citizenship Studies, 5:3, 237-253

PNDH (2014). Programa Nacional de Derechos Humanos 2014-2018, publicado en el Diario Oficial de la Federación el 30 de abril de 2014, disponible en <http://bit.ly/1rJbJOy>, página consultada el 23 de septiembre de 2019.

Preciado, B. (2008). Testo yonqui. Madrid: Espasa Calpe.

Preciado, P. B. (2019). Un apartamento en Urano. Crónicas del cruce. México: Anagrama.

Programa Nacional de Desarrollo (2001-2006). Recuperado de; http://planeacion.uaemex.mx/InfBasCon/PlanNacionaldeDesarrollo2000-2006.pdf

Programa Nacional de Desarrollo (2007-2012). Recuperado de: http://pnd.calderon.presidencia.gob.mx/pdf/pnd_2007-2012.pdf

Programa Nacional de Desarrollo (2013-2018). Recuperado de: http://pnd.gob.mx/

Programa Nacional de Desarrollo (2019-2024) Recuperado de: https://lopezobrador.org.mx/wpcontent/uploads/2019/05/PLAN-NACIONAL-DE-DESARROLLO-2019-2024.pdf

PRONAID (2014). Programa Nacional para la Igualdad y No Discriminación 2014, publicado en el Diario Oficial de la Federación el 30 de abril de 2014, disponible en <http://bit.ly/1rJbzqo >, página consultada el 23 de septiembre de 2019.

Prunas, A., et al. (2014). Defensive functioning in MtF and FtM transsexuals. Comprehensive psychiatry, 55(4), 966-971.

Raupp, R. (2004). Apuntes para un derecho democrático de la sexualidad. En Cáceres, C. F., Frasca, T., Pecheny, M., \& Terto Júnior, V. Ciudadanía sexual en América Latina: abriendo el debate. Lima, Perú. Universidad Peruana Cayetano Heredia.

Richardson, D. (1998) Sexuality and citizenship. Sociology 32(1): 83-100

Richardson, D. (2000) Constructing sexual citizenship: Theorizing sexual rights. Critical Social Policy 20(1): 105-135.

Richardson, D. (2017). Rethinking Sexual Citizenship. Sociology, 51(2), 208-224.

Richardson, D. (2018). Sexuality and citizenship. Sexualities, 0(0) 1-5. 
Richardson, D. y Monro, S. (2012). Sexuality, Equality and Diversity. Basingstoke: Palgrave Macmillan.

Rimes, K. A., Goodship, N., Ussher, G., Baker, D., y West, E. (2019). Non-binary and binary transgender youth: Comparison of mental health, self-harm, suicidality, substance use and victimization experiences. International Journal of Transgenderism, 20(2-3), 230-240.

Robles, R., y Ayuso-Mateos, J. L. (2019). CIE-11 y la despatologización de la condición transgénero. Revista de Psiquiatría y Salud Mental, 12(2), 65-67.

Rosales, A.L. (2007). Democracia y ciudadanía sexual en el contexto de la incorporación del género y las sexualidades en instituciones de educación superior publica en México. Primer coloquio nacional de género y educación. Universidad Pedagógica Nacional.

Rosales-Cueva, J. H. (2008). Sábanas y chocolate. Cuerpo, placer y palabra. Revista S, 177-190.

Rueda, A. (2015) Derechos de las personas Trans. Defensor. Revista Mensual de la Comisión de Derechos Humanos del Distrito Federal. 3, XIII, 41-47.

Ryan-Flood R (2009) Lesbian Motherhood: Gender, Families and Sexual Citizenship. Basingstoke: Palgrave Macmillan.

Sabsay, L. (2018). Imaginarios sexuales de la libertad: performatividad, cuerpos y fronteras. Debate Feminista, 55, 1-26.

Scott, J. W. (2008). Género e historia. México: Fondo de cultura económica.

Secretaría de Gobernación (2019). Plan Nacional de Desarrollo 2019-2024. Diario Oficial de la Federación.

Sedwick, E. K. (1990). Epistemology of the Closet. Londres: University of California Press.

Segovia, S. y Guillamón, A. (1993). Sexual dimorphism in the vomeronasal pathway and sex differences in reproductive behaviors. Brain Research Reviews, 18, 51- 74.

Shepard, B. (2004). Pecado y derechos humanos: la falta de Ciudadanía sexual de la juventud. En Cáceres, C. F., Frasca, T., Pecheny, M., y Terto Júnior, V. Ciudadanía sexual en América Latina: abriendo el debate. Lima, Perú. Universidad Peruana Cayetano Heredia.

Siebers. T. (2008). Disability Theory. Ann Arbor, MI: University of Michigan Press.

Smith, E. S., Junger, J., Derntl, B. y Habel, U. (2015). The transsexual brain-A review of findings on the neural basis of transsexualism. Neuroscience \& Biobehavioral Reviews, 59, 251-266.

Stewart, L., O'Halloran, P., y Oates, J. (2018). Investigating the social integration and wellbeing of transgender individuals: A meta-synthesis. International Journal of Transgenderism, 19(1), 46-58.

Stewart, M. (1999). La verdad sobre todo. Una historia irreverente de la filosofía, Ciudad de México: Taurus.

Stoller, R. J. (1968). Sex and gender. Vol. II. The transsexual experiment. Londres: Hogart Press.

Suárez-Villegas, J. C. (2006). La mujer construida. Comunicación e identidad femenina. Alcalá de Guadaira, Sevilla: MAD-Eduforma.

Suprema Corte de Justicia de la Nación. (2018). Intersexualidad en México y el problema de la sexualidad binaria. Recuperado en red el 17 de febrero de 2019 . En: https://www.scjn.gob.mx/sites/default/files/igualdad-genero/2018-

06/ENSAYO\%20TERCER\%20LUGAR\%20Intersexualidad\%20en\%20México_0.pdf 
Susen, S. (2010). The transformation of citizenship in complex societies. Journal of Classical Sociology, 10(3), 259-285.

Swaab, D. F. (2007). Sexual differentiation of the brain and behavior. Best Practice \& Research Clinical Endocrinology \& Metabolism, 21, 431-44.

Tallis, J. (2005). Sexualidad y discapacidad. Miño y Dávila editores.

Theisen, J. G., Et al. (2019). the Use of Whole exome Sequencing in a cohort of transgender individuals to identify Rare Genetic Variants. Scientific Reports, 9(1), 1-11.

Valadez-Blanco, O., y McManus, F. G. (2014). Biología, reificación y transdisciplina: Hacia una visión crítica de las ontologías y los conflictos científicos. Metatheoria-Revista de Filosofía e Historia de la Ciencia, 5(1), 113-126.

Vilchis, L. M. G. (2017). Reflexiones sobre políticas públicas: diversidad sexual en México. El Cotidiano, (202), 73-83.

Waites, M. (1996). Lesbian and gay theory, sexuality and citizenship. Contemporary Politics, 2(3), 139-149.

WAS \& OPS. (2009). Salud sexual para el milenio Declaración y documento técnico. Recuperado en red el 5 de marzo de 2019.2 En: http://www1.paho.org/hq/dmdocuments/2010/Salud\%20Sexual\%20para\%20el\%20Milenio.pdf

Weeks, J. (1998). The Sexual Citizen. Theory Culture Society, 15(35), 35-52.

Weeks, J. (2018). Sexual studies and sexual justice. Sexualities, 0(0) 1-5.

Weston, K. (1993). Lesbian / Gay Studies in the House of Anthropology. Annual Review of Anthropology 22: 339-367. doi: 10.1146/annurev.an.22.100193.002011

Whittle, S. (2002). Respect and Equality: Transsexual and Transgender Rights. London: Cavendish, Publishing.

Wittig, M. (2006). El pensamiento heterosexual y otros ensayos. Beacon Press. Boston.

Woolfolk, L.E., Núñez, G. y Ponce, P. (2016). Sexualidad, desarrollo, políticas públicas y turismo LGBTTTI en México, Revista Turydes: Turismo y Desarrollo, n. 21

Yue A y Zubillaga-Pow, J. (2012). Queer Singapore: Illiberal Citizenship and Mediated Cultures. Hong Kong: Hong Kong. University Press.

Zarazúa, C. J., Salinas, M. R., Negrete, K. M., y Ruíz, J. M. (2015). La evaluación multidisciplinaria en disforia de género: reporte de caso y revisión de la literatura. Biomedicina, 1.

Zubiaurre-Elorza, L., et al. (2013). Cortical Thickness in Untreated Transsexuals. Cerebral Cortex, 23. 